\title{
CADEIA VERDE DE SUPRIMENTOS: ASSOCIAÇÕES ENTRE DIRECIONADORES, PRÁTICAS E DESEMPENHO
}

\author{
GREEN SUPPLY CHAIN: ASSOCIATIONS AMONG DRIVERS, \\ PRACTICES AND PERFORMANCE
}

\section{CADENA DE ABASTECIMIENTO VERDE: ASOCIACIONES ENTRE CONDUCTORES, PRÁCTICAS Y DESEMPEÑO}

\author{
Gustavo Neves Goularte \\ Mestre em Desenvolvimento Territorial e Sistemas \\ Agroindustriais \\ Analista de meio ambiente na empresa Terminal de \\ Containers de Rio Grande (TECON-Rio Grande) \\ gngoute@gmail.com \\ Marcelo Fernandes Pacheco Dias \\ Professor de Ciências Sociais Agrárias da Universidade \\ Federal de Pelotas \\ Pós-doutor na Universidade de Sussex \\ Doutor em Agronegócios (CEPAN/UFRGS) \\ mfpdias@hotmail.com
}

\author{
Contextus \\ ISSNe 2178-9258 \\ Organização: Comitê Científico Interinstitucional \\ Editor-Chefe: Diego de Queiroz Machado \\ Avaliação: double blind review pelo SEER/OJS \\ Recebido em 07/05/2019 \\ Aceito em 13/06/2019 \\ Versão final em 06/07/2019 \\ http://dx.doi.org/10.19094/contextus.v17i2.41193
}

\section{RESUMO}

Esta pesquisa teve como objetivo analisar quais são e como se associam entre si os direcionadores externos e internos, as práticas verdes e o desempenho econômico e ambiental numa cadeia verde de suprimentos (Green Supply Chain Management - GSCM). A motivação do estudo reside no número limitado de estudos sobre como os elementos de uma GSCM se associam entre si e principalmente no setor portuário. Para atender a este objetivo, foi realizado um estudo de caso na cadeia verde de suprimentos do Terminal de Contêineres do Porto de Rio Grande. Como resultado, foi possível identificar um sistema complexo de partes (direcionadores externos, internos, práticas e indicadores de desempenho) e associações que envolve a GSCM estudada. Evidenciaram-se associações específicas entre direcionadores e práticas desenvolvidas, bem como entre práticas de GSCM e os indicadores de desempenho. Há práticas que contribuem para ambos os desempenhos. Os direcionadores externos podem condicionar diretamente a presença de indicadores de desempenho.

Palavras-chave: cadeia verde de suprimentos; desempenho; direcionadores; práticas verdes; porto.

\begin{abstract}
The research objective was to analyze external and internal drivers, green practices and economic and environmental performance in a green supply chain management - GSCM. The motivation of the study lies in the limited number of studies on how the elements of a GSCM associate with one another and especially in the port sector. To meet this objective, a case study was carried out in the green supply chain of the Container Terminal of the Port of Rio Grande. As a result, it was possible to identify a complex system of parts (external drivers, internal, practices and performance indicators) and associations involving the studied GSCM. There was evidence of specific associations between drivers and practices and between practices and GSCM performance indicators. There are practices that contribute to both performances. External drivers can directly condition the presence of performance indicators.
\end{abstract}

Keywords: green supply chain; performance; drivers; green practices; port.

\section{RESUMEN}

El presente trabajo tiene por objetivo analizar cuáles son y cómo se asocian entre sí los conductores externos e internos, las prácticas verdes y el desempeño ambiental en una cadena de abastecimiento verde - GSCM. Motiva este estudio, el número limitado de investigaciones sobre la forma en que se asocian los elementos de una GSCM, principalmente en el sector portuario. Para atender este objetivo, se realizó un estudio de caso en la cadena de 
abastecimiento verde de la Terminal de Contenedores del Puerto de Río Grande. Como resultado, fue posible identificar un sistema complejo de partes (conductores externos, internos, prácticas e indicadores de desempeño) y asociaciones involucradas en la GSCM estudiada. Se evidenciaron asociaciones específicas entre los conductores y las prácticas desarrolladas, y entre las prácticas de GSCM y los indicadores de desempeño. Hay prácticas que contribuyen para ambos desempeños. Los conductores externos pueden condicionar directamente la presencia de indicadores de desempeño.

Palabras clave: cadena de abastecimiento verde; desempeño; conductores; prácticas verdes; puerto.

\section{INTRODUÇÃO}

O Gerenciamento da Cadeia Verde de Suprimentos ou Green Supply Chain Management (GSCM) surgiu como um novo arquétipo que pode ser utilizado pelas empresas para que essas tenham condições de atingir os objetivos financeiros e de market share pela diminuição de seus riscos e impactos ambientais. GSCM é definida como a integração da preocupação ambiental nas práticas interorganizacionais de gestão da cadeia de suprimentos (SRIVASTAVA, 2007).

Jabbour et al. (2013) destacam que os principais temas de pesquisa sobre GSCM são as práticas, direcionadores internos e externos, barreiras e desempenho. Franco et al. (2017) ao analisar estes temas individualmente, constata que os direcionadores são um dos temas menos estudados e ao analisar as relações entre os temas constata que também há poucos estudos que abordam as relações entre as práticas, os direcionadores e os desempenhos. Além disso, os poucos estudos sobre a relação entre as práticas e os desempenhos são inconclusivos. Estes estudos concentraram-se apenas no desempenho ambiental, econômico e operacional do GSC (HUANG et al., 2017).

Quando se analisa os objetos de estudos pesquisados por Jabbour et al. (2013) constata-se que o elo industrial é o mais estudado. Neste elo, o setor eletroeletrônico apresentou $56 \%$ de frequência. Os outros dois setores que se destacaram foram o automotivo e o químico, com $44 \%$ e $40 \%$ de ocorrência, respectivamente, e houve escassas pesquisas no setor portuário, foco deste artigo (JABBOUR et al., 2013). Em relação à região destas pesquisas, Fahimnia et al. (2015) constatam que é necessário conhecer mais sobre gerenciamento da cadeia verde de suprimentos na América do Sul, que é uma das regiões menos estudadas do mundo, representando apenas $2,1 \%$ da literatura disponível sobre o assunto. Em termos metodológicos, Franco et al. (2017) recomenda o método estudo de caso, já que este é pouco utilizado e este poderia contribuir para a compreensão das associações entre os direcionadores, práticas e desempenho, principalmente no Brasil. Compreender as associações entre direcionadores, práticas e desempenho pode contribuir para revelar quais práticas podem contribuir para o 
desempenho econômico das organizações, que até então, tem sido considerado inconclusivo (HUANG et al., 2017).

A partir destes resultados encontrados sobre o estado da arte da GSCM, estabeleceuse como questão de pesquisa: Como se associam os fatores externos e internos à organização, a adoção de práticas verdes e o desempenho econômico e ambiental numa cadeia verde de suprimentos? Foi realizado um estudo de caso no Terminal de Contêineres do Porto de Rio Grande, Rio Grande do Sul, que teve por objetivo analisar como se associam entre si os direcionadores externos e internos às práticas verdes e ao desempenho econômico e ambiental numa cadeia verde de suprimentos.

O Terminal de Contêineres do Porto de Rio Grande (TECON Rio Grande) é o único terminal de contêineres do Estado do Rio Grande do Sul. O TECON movimenta cerca de 99\% dos contêineres do porto de Rio Grande. No ano de 2015 movimentou 443.471 contêineres, onde a exportação representou cerca de $70 \%$ deste volume. Os portos estão localizados em ambientes naturais de considerável valor ecológico.

Por ser um ambiente de especificidade significativa (ecossistemas marinhos, fauna, flora, regulação sanitária), estes são locais altamente regulados (ANTAQ, 2013). Órgãos federais como o Instituto Brasileiro do Meio Ambiente (IBAMA), Agência Nacional de Vigilância Sanitária (ANVISA), Ministério da Agricultura, Pecuária e Abastecimento (MAPA) e Receita Federal atuam diretamente na regulação, por meio de legislações, resoluções e normativas à serem cumpridas pelos empreendimentos que exercem suas atividades nesses ambientes (GUSMÃO; MARTINI, 2009). Nesses espaços, pelo tipo de atividade desenvolvida, a geração de resíduos e efluentes, emissão de gases do efeito estufa, consumo de recursos naturais (água, combustíveis fósseis), consumo de energia elétrica, além do risco de vazamentos de óleo em água são alguns pontos que demonstram o porquê destes locais possuírem forte pressão pela adoção de práticas de GSCM (ANTAQ, 2013). Por fim, considerando as conclusões de Jabbour et al. (2013), Fahimnia et al. (2015) e Franco et al. (2017), Este artigo quer contribuir para identificar os direcionadores internos e externos, práticas ambientais e desempenho econômico e ambiental no setor portuário, assim como identificar e descrever as associações existentes entre essas partes, principalmente sobre quais são e como as práticas contribuem para o desempenho ambiental e quais e como contribuem para o desempenho econômico. 


\section{REFERENCIAL TEÓRICO}

Nesta seção, são discutidas as práticas de GSCM (Subseção 2.1), os direcionadores externos e internos (Subseção 2.2), e indicadores de desempenho ambiental e econômico (Subseção 2.3).

\subsection{Práticas de GSCM}

A GSCM é considerada uma abordagem conceitual híbrida ao integrar fundamentos de gestão ambiental com pressupostos de gestão da cadeia de suprimentos (SRIVASTAVA, 2007). Esse arquétipo leva em consideração a preocupação ambiental em atividades de cadeia de suprimentos, como por exemplo: projeto do produto; compras; manufatura; transporte e marketing; e logística reversa.

A GSCM tem por objetivo integrar as operações fabris com as questões ambientais, a fim de reduzir custos operacionais do ciclo de vida do produto e, ao mesmo tempo, diminuir a geração de poluição e resíduos e de consequentes problemas de saúde (ARANTES et al., 2014). A importância do tema ambiental na definição de estratégias pelas organizações pode levar a uma melhora no desempenho ambiental e econômico da empresa (DELIBERAL et al., 2016).

Há várias práticas de GSCM citadas na literatura. Zhu et al. (2008) conseguiram, por meio de uma survey, validar estatisticamente uma síntese, sendo estas práticas: gestão ambiental interna, cooperação com cliente, ecodesign e logística reversa.

A gestão ambiental interna é considerada o primeiro passo para a implementação e adoção de práticas de GSCM. Na gestão ambiental, são adotados programas e ações internas com o comprometimento da alta e média administração, bem como dos colaboradores da empresa. A gestão ambiental pode exigir que seus fornecedores domésticos e externos participem das ações e assumam compromissos ambientais também (SILVA JÚNIOR et al., 2009; AZEVEDO et al., 2011). De acordo com Azevedo et al. (2011) e Hsu et al. (2013) a adoção do sistema de gestão ambiental (SGA), com base no padrão ISO 14.001, é uma prática recorrente da GSCM nas empresas. A norma ISO 14.001 é um padrão reconhecido internacionalmente que define os critérios para um sistema de gestão ambiental, exigindo compromisso com o cumprimento da legislação aplicável, regulamentos e melhoria contínua. 
Ela constitui a base para uma abordagem sistemática para a redução dos impactos nas organizações (ABNT, 2015).

A cooperação com cliente inclui o intercâmbio de informações técnicas e operacionais a fim de planejar e operacionalizar metas ambientais (SILVEIRA et al., 2010; ARANTES et al., 2014). Azevedo et al. (2011) e Silveira et al. (2010) indicam que uma relação de cliente eficaz permite a redução de custo da cadeia de suprimentos e mantém a confiabilidade das operações, aumentando assim a qualidade e a satisfação do cliente. Esta prática verde aumenta o nível de consciência ambiental e torna os clientes parceiros ambientais, maximizando os volumes de retorno, reduzindo o desperdício de negócios e os custos ambientais e aumentando a satisfação do cliente. Isso ajuda a aumentar a capacidade de resposta às preocupações ambientais dos clientes, bem como melhorar a taxa de atendimento e entrega no prazo (AZEVEDO et al., 2011).

O ecodesign tem como objetivo criar produtos ecoeficientes, sem comprometer seus custos, qualidade e restrições de tempo para a fabricação (ARANTES et al., 2014). Um dos pontos chave é facilitar o reuso, a reciclagem e recuperação dos resíduos (DIABAT; GOVINDAN, 2011). Organizações ambientalmente proativas reconhecem que é fundamental desenvolver uma relação de trabalho saudável com os consumidores, fornecedores e autoridades governamentais para que o ecodesign se torne parte integrante das iniciativas da GSCM (HSU et al., 2013).

A logística reversa é o processo de planejar, implantar e controlar o fluxo de materiais, inventários, bens acabados e informações do produto durante a sua utilização e descarte adequado (DIABAT; GOVINDAN, 2011; ARANTES et al., 2014). A logística reversa exige atenção significativa por parte dos profissionais de logística. Empresas que desejam fazer negócios em muitos países devem lidar com os resíduos de embalagem, bem como resolver a questão da satisfação do cliente de produtos recuperáveis (HSU et al., 2013).

Além das práticas identificadas por Zhu et al. (2008), pode-se acrescentar ainda como práticas da GSCM: a minimização de resíduos, diminuir o consumo de materiais perigosos e tóxicos (AZEVEDO et al., 2011), a substituição de insumo (ZHU et al., 2005) e a redução de riscos (SOUZA, 2013).

A minimização de resíduos envolve o manuseamento e minimização de resíduos. Essa prática verde também é incorporada em práticas enxutas para a eliminação de atividades de desperdício ou não valorizadas em toda a cadeia. Juntamente com a sua contribuição para a 
redução dos custos ambientais, também diminui o desperdício de negócios e promove melhorias de eficiência no processo da cadeia de suprimentos e redução de custos financeiros (AZEVEDO et al., 2011).

A diminuição do consumo de materiais perigosos e tóxicos pode ajudar a minimizar o custo de eliminar e tratar esses materiais, assim como limita o desperdício. No entanto, embora esta prática possa ser adotada por uma organização individual, ela só produzirá o desempenho ambiental desejado se os fornecedores com preocupações ambientais também estiverem envolvidos. Este tipo de prática só é possível se todos os parceiros no gerenciamento da cadeia de suprimentos partilham as mesmas preocupações ambientais (AZEVEDO et al., 2011).

Zhu et al. (2005) destacam que a substituição de insumos também pode ser uma ação estratégica vinculada à redução dos impactos ambientais e que podem fornecer vantagem competitiva para a empresa, bem como novas maneiras de agregar valor ao produto/serviço realizado. E por fim, a gestão de riscos possibilita uma menor probabilidade de interrupções na cadeia de suprimentos (AZEVEDO et al., 2011).

\subsection{Direcionadores Externos e Internos da GSCM}

A adoção de práticas ambientais pode surgir das partes interessadas (stakeholders). A maioria dos países desenvolvidos e em desenvolvimento já criaram regulamentos que exigem que as empresas façam políticas ecológicas para sua cadeia de suprimentos. Assim, as empresas são obrigadas a implementar estratégias verdes devido ao aumento da pressão externa para a sustentabilidade sob a forma de medidas ambientais obrigatórias que estão diretamente relacionados à GSCM (LEE et al., 2013).

Estas pressões para a adoção de práticas verdes são definidas como direcionadores, os quais podem ser externos e internos. Hsu et al. (2013) descrevem como direcionadores externos as medidas regulamentares, as exigências dos clientes, bancos e bolsa de valores e as empresas concorrentes.

As medidas regulamentares são mecanismos oficiais que assumem a forma de normas, leis, procedimentos e incentivos estabelecidos pelas instituições reguladoras para empresas a se tornarem ambientalmente responsáveis. As exigências impostas pelo governo e pelos órgãos reguladores fornecem incentivos para que as empresas adotem a GSCM (HSU et al., 2013). As pressões dos clientes advêm do questionamento dos clientes sobre o efeito ambiental dos bens 
que compram e esperam que as empresas busquem um padrão verde mínimo em seus projetos de produtos e processos (HSU et al., 2013). As pressões de bancos e de bolsas de valores são grupos de interesses sensíveis e influenciados por qualquer comportamento realizado pela empresa. Assim, a imagem da empresa interfere na oferta de financiamentos e compra e valor das ações (HSU et al., 2013). As pressões dos concorrentes ocorrem quando as empresas grandes e bem-sucedidas em uma indústria, geralmente, enfrentam escrutínio intenso de concorrentes e ativistas ambientais externos. Dessa forma, muitas organizações trabalham em um ambiente que inclui pressões de seus concorrentes que induzem as organizações a adotarem iniciativas para vencer a concorrência e obter vantagens competitivas junto ao mercado (HSU et al., 2013).

Diabat e Govindan (2011) acrescentam também que os fornecedores podem exigir a certificação do sistema de gestão e este pode ser um direcionador importante para a adoção da GSCM. Além disso, Chien e Shih (2007) citam que a comunidade vizinha também pode direcionar medidas de implantação de práticas de GSCM.

A adoção de práticas ambientais pode surgir também de direcionadores internos à organização. Foram identificados na literatura quatro deles associados às práticas de GSCM. São eles: direção, recursos financeiros, recursos humanos e tecnologia.

A direção pode contribuir para a formação de valores organizacionais que suportem a implementação de práticas de GSCM através do suporte aos gestores de nível superior e médio na gestão do ambiente interno ao atendimento de objetivos ambientais e gestão do conhecimento (JABBOUR et al., 2013; FRANCO et al., 2017).

A disponibilidade de recursos humanos envolve a disponibilidade na empresa de Capital humano capacitado com informações e conhecimento sobre práticas de GSCM e capazes de identificar oportunidades, gerenciar mudanças com vista a implementar novos processos organizacionais (JABBOUR; SOUZA, 2015; LUTHRA et al., 2016).

Recursos financeiros se referem à disponibilidade de ativos da empresa, para a implantação das práticas de GSCM (JABBOUR; SOUZA, 2015; LUTHRA et al., 2016). Por fim, a disponibilidade de recursos tecnológicos envolve a presença na empresa de tecnologias capazes de contribuir para a ecoeficiência organizacional (JABBOUR; SOUZA, 2015). 


\subsection{Indicadores de Desempenho Ambiental e Econômico}

Pode-se afirmar que o objetivo das corporações que implementam o GSCM é de melhorar o desempenho ambiental e econômico de sua instituição. As atividades de gestão ambiental realizadas em uma organização podem refletir positivamente, além do desempenho ambiental, no desempenho econômico, visto que a abordagem sustentável, além de prover uma economia de custos, (prevenção de sinistros) também pode levar a organização a alcançar novos mercados. (CHIEN; SHIH, 2007).

A norma ABNT ISO 14001 define o desempenho como um resultado mensurável, relacionando tanto a constatações quantitativas como qualitativas de um sistema de gestão ambiental. A mesma norma indica que a organização para ser certificada necessita atender a legislação aplicável aos negócios (requisitos legais), dentre outros parâmetros estipulados (ABNT, 2015).

Especificamente, o desempenho ambiental é definido pela norma ISO 14.001 (2015), como os resultados mensuráveis da gestão dos aspectos ambientais de uma organização, que podem ser confrontados com a política ambiental e com os objetivos ambientais estipulados pela organização. Assim, o desempenho ambiental pode ser descrito como a informação analítica oferecida por um conjunto de indicadores que permite comparar entre si, ou contra uma referência externa, requisitos ambientais em setores de uma empresa, ou em empresas de uma indústria (ANTONOV; SELLITTO, 2011).

Os indicadores demonstram o que se deve medir para que se possa concluir sobre o desempenho da organização. Estes podem ser econômicos e ambientais. Os ambientais estão relacionados principalmente ao consumo de materiais, gestão de energia, geração de resíduos e emissões e avaliação de aspectos ambientais das organizações e contribuições para a organização da gestão ambiental global (CHIEN; SHIH, 2007). De acordo com (ANTONOV; SELLITTO, 2011), o desempenho ambiental pode ser medido em resíduos sólidos, efluentes, recursos naturais, emissões atmosféricas e legislação. A norma ISO 14.001 (2015) acrescenta que a empresa pode adicionar requisitos que não sejam legais, mas que a empresa opta por cumprir (ABNT, 2015, p. 16), tais como gestão de riscos (AZEVEDO, 2011). Em relação aos indicadores econômicos, Chien e Shih (2007) definem os seguintes parâmetros que podem ser utilizados por uma organização que vislumbra implementar o GSCM: redução de custos; aumento na participação do mercado; aumento da margem de lucro. 


\section{METODOLOGIA}

A definição da estratégia a ser abordada nesta pesquisa foi classificada como uma abordagem qualitativa em um estudo de caso único. O estudo de caso pode ser caracterizado como o estudo de uma entidade definida como, por exemplo, uma empresa ou uma unidade social, que possui como principal objetivo conhecer em profundidade uma determinada situação que se supõe ser única, procurando descobrir a principal característica que a leva ser única (YIN, 2009). O caso selecionado foi o TECON Rio Grande S.A - Terminal de Contêineres do Porto de Rio Grande - RS. Foi definida está empresa, haja vista o reconhecimento que ela tem na adoção de práticas de GSCM e a sua importância na cadeia logística do estado do Rio Grande do Sul.

O Terminal de Contêineres de Rio Grande é uma empresa constituída a partir de um único acionista, Wilson, Sons, o qual tem ações comercializadas na bolsa de São Paulo e de Londres. A empresa venceu a licitação do Terminal de Contêineres do Porto do Rio Grande e passou a administrá-lo a partir de 1997 por 25 anos, renováveis por igual período (TECON, 2017). O TECON RG iniciou suas atividades com 64 pessoas, e atualmente possui cerca de 900 colaboradores. Movimenta 98\% da carga conteinerizada que passa pelo Porto do Rio Grande, o TECON RG tem como seu maior objetivo concentrar a carga dos países do Cone Sul, claramente suportado pelas facilidades físicas e geográficas pelos investimentos realizados e pelo preço competitivo (TECON, 2017).

A coleta de dados teve início no ano de 2017, por meio de documentos, entrevistas e observação participante. A seguir são listados quais os documentos foram analisados durante a pesquisa (Quadro 1).

Quadro 1 - Documentos analisados durante a pesquisa

\begin{tabular}{|l|l|}
\hline \multicolumn{1}{|c|}{ Documento analisados durante a pesquisa: } & \multicolumn{1}{|c|}{$\begin{array}{c}\text { Tipo de } \\
\text { Documento }\end{array}$} \\
\hline $\begin{array}{l}\text { Terceiro relatório da qualidade do ar - TECON Rio } \\
\text { Grande S.A }\end{array}$ & Interno \\
\hline Portaria FEPAM n/ 06/2018 & Interno \\
\hline Autorização Geral FEPAM n ${ }^{\circ} 222 / 2013-$ DL & Interno \\
\hline Autorização Geral FEPAM n ${ }^{\circ} 46 / 2017$ - DL & Interno \\
\hline $\begin{array}{l}\text { E-mail interno - Questionário Terminal TECON Rio } \\
\text { Grande }\end{array}$ & Interno \\
\hline Licença de Operação FEPAM LO 3241/2016-DL & Interno
\end{tabular}

(CONTINUA) 
(CONTINUAÇÃO)

\begin{tabular}{|l|l|}
$\begin{array}{l}\text { Arquivo Excel Identificação e Hierarquização das } \\
\text { Partes Interessadas }\end{array}$ & Interno \\
\hline Certificado ISO 14.001: 2015 & Interno \\
\hline $\begin{array}{l}\text { Instrução de Trabalho IT-SEG 25- Identificação e avaliação de perigos e } \\
\text { riscos à segurança e saúde ocupacional }\end{array}$ & Interno \\
\hline $\begin{array}{l}\text { Instrução de Trabalho IT-AMB 02- Plano de Gerenciamento de Resíduos } \\
\text { Sólidos - PGRS. }\end{array}$ & Interno \\
\hline $\begin{array}{l}\text { Instrução de Trabalho IT-AMB-06- Procedimento para Transporte Interno } \\
\text { e Armazenamento de Resíduos Contaminados. }\end{array}$ & Interno \\
\hline $\begin{array}{l}\text { Instrução de Trabalho IT-AMB-08- Identificação e } \\
\text { Avaliação de Aspectos e Impactos Ambientais }\end{array}$ & Interno \\
\hline $\begin{array}{l}\text { Instrução de Trabalho IT-MAN 02- Atividades de } \\
\text { Lavagem }\end{array}$ & Interno \\
\hline $\begin{array}{l}\text { Instrução de Trabalho IT-SEG 23- Gestão de Crise } \\
\text { Instrução de Trabalho IT-AMB 03- coleta seletiva de resíduos - setores } \\
\text { administrativos }\end{array}$ & Interno \\
\hline $\begin{array}{l}\text { Instrução de Trabalho IT-AMB 10- Unidade de } \\
\text { Compostagem }\end{array}$ & Interno \\
\hline $\begin{array}{l}\text { PG-COM- Procedimento de Gestão - Processo } \\
\text { Compras }\end{array}$ & Interno \\
\hline Questionário Financiamento & Interno \\
\hline $\begin{array}{l}\text { PG-SMS- Processo de Saúde Ocupacional, Meio } \\
\text { Ambiente e Segurança do Trabalho }\end{array}$ & Interno \\
\hline $\begin{array}{l}\text { Lista de fornecedores qualificados } \\
\text { Laudo análise caixa separadora água-óleo }\end{array}$ & Interno \\
\hline
\end{tabular}

Fonte: elaboração própria.

As entrevistas foram elaboradas através de roteiro semiestruturado com 4 perguntas principais para identificação e descrição dos direcionadores, práticas de GSCM e indicadores de desempenho ambiental e econômico. Além destas questões foram realizadas mais 4 perguntas abertas para a compreensão das associações existentes entre as partes. $\mathrm{O}$ entendimento das questões foi previamente testado e adequado com um dos entrevistados (analista de meio ambiente). A partir daí, o roteiro utilizado foi idêntico para todos os entrevistados. Todos os entrevistados foram informados do motivo da entrevista e da gravação dela, por motivo de transcrição mais fidedigna e para que a fala dos entrevistados pudesse compor os documentos desta pesquisa. As seguintes questões foram realizadas nas entrevistas e análise de documentos:

1. Quais são as práticas verdes adotadas? As categorias analisadas foram: sistema de gestão ambiental - SGA), cooperação com o cliente (AZEVEDO et al., 2011; LEE et al., 2013; 
ARANTES et al., 2014), logística reversa e disposição adequada de resíduos (AZEVEDO et al., 2011; DIABAT; GOVINDAN, 2011; HSU et al., 2013; ARANTES et al., 2014), minimização de resíduos (AZEVEDO et al., 2011), substituição de insumos (ZHU et al., 2005), gestão de riscos (SOUZA, 2013), ecodesign (DIABAT; GOVINDAN, 2011; HSU et al., 2013; ARANTES et al., 2014) e diminuição do consumo de materiais perigosos e tóxicos (AZEVEDO et al., 2011).

2. Quais são os direcionadores externos e como levam a empresa a adotar práticas verdes? As categorias analisadas foram: medidas regulamentares (CHIEN; SHIH, 2007; DIABAT; GOVINDAN, 2011; HSU et al., 2013; SOUZA, 2013; JABBOUR; SOUZA, 2015) vizinhança (JABBOUR; SOUZA, 2015); bancos, acionistas e clientes (CHIEN; SHIH, 2007; HSU et al., 2013; JABBOUR; SOUZA, 2015), fornecedores (DIABAT; GOVINDAN, 2011) e concorrentes (CHIEN; SHIH, 2007; DIABAT; GOVINDAN, 2011; HSU et al., 2013; JABBOUR; SOUZA, 2015).

3. Quais são os fatores internos e como levam a empresa a adotar práticas verdes? As categorias analisadas foram: disponibilidade de recursos humanos (JABBOUR; SOUZA, 2015; LUTHRA et al., 2016), disponibilidade de recursos tecnológicos (JABBOUR; SOUZA, 2015), direção (JABBOUR et al., 2013; JABBOUR; SOUZA, 2015; LUTHRA et al., 2016; FRANCO et al., 2017); disponibilidade de recursos financeiros (JABBOUR; SOUZA, 2015; LUTHRA et al., 2016).

4. Como é avaliado o desempenho ambiental e econômico da GSCM? As categorias analisadas foram: 1) indicadores ambientais: efluentes (ANTONOV; SELLITTO, 2011), legislação ambiental, resíduos sólidos (CHIEN; SHIH, 2007; ANTONOV; SELLITTO, 2011), emissões atmosféricas, e recursos naturais (CHIEN; SHIH, 2007; ANTONOV; SELLITTO, 2011); 2) indicadores econômicos: redução de custos, margem de lucro e aumento na participação de mercado (CHIEN; SHIH, 2007).

5. Na sua avaliação, existem relações entre os fatores externos elencados e as práticas de GSCM? Caso positivo, explique esta relação.

6. Na sua avaliação, existem relações entre os fatores internos elencados e as práticas de GSCM? Caso positivo, explique esta relação.

7. $\mathrm{Na}$ sua avaliação, existem relações entre as práticas de GSCM elencadas e os indicadores de desempenho econômico e ambiental da GSCM? Caso positivo, explique esta relação.

8. Na sua avaliação, existem outras associações entre os direcionadores internos, externos, práticas de GSCM e indicadores da GSCM? Caso positivo, explique esta relação. 
No processo de entrevista foram esclarecidas as dúvidas dos entrevistados quanto ao entendimento da questão e perguntado a cada um deles sobre cada uma das categorias associadas às quatro perguntas. Os entrevistados foram selecionados por serem de pessoas que estão envolvidas de maneira consistente com as decisões empresariais tomadas no TECON Rio Grande S.A, de tal forma que, pelos seus cargos e tempo de trabalho na empresa participaram, tanto da implantação, como da avaliação da GSCM. Abaixo o Quadro 2 com os dados da entrevista.

Quadro 2 - Dados dos agentes entrevistados

\begin{tabular}{|l|l|l|l|l|}
\hline $\begin{array}{c}\text { Código } \\
\text { entrevista }\end{array}$ & \multicolumn{1}{|c|}{ Data } & \multicolumn{1}{c|}{ Cargo } & \multicolumn{1}{c|}{$\begin{array}{c}\text { Tempo } \\
\text { empresa }\end{array}$} & \multicolumn{1}{c|}{$\begin{array}{c}\text { Duração } \\
\text { entrevista }\end{array}$} \\
\hline Entrevista 1 & $24 / 04 / 2018$ & Analista Meio Ambiente & 17 anos & 50 minutos \\
\hline Entrevista 2 & $07 / 05 / 2018$ & $\begin{array}{l}\text { Gerente de Saúde, Meio } \\
\text { Ambiente e Segurança }\end{array}$ & 9 anos & 40 minutos \\
\hline Entrevista 3 & $14 / 06 / 2018$ & Gerente de Manutenção & 20 anos & 55 minutos \\
\hline Entrevista 4 & $14 / 06 / 2018$ & Gerente de Operações & 21 anos & 22 minutos \\
\hline Entrevista 5 & $15 / 06 / 2018$ & $\begin{array}{l}\text { Gerente Corporativo de } \\
\text { Saúde, Meio Ambiente e } \\
\text { Segurança }\end{array}$ & 9 anos & 57 minutos \\
\hline
\end{tabular}

Fonte: elaboração própria.

As entrevistas foram transcritas, analisadas e inseridas no software NVIVO. A elaboração das categorias no software foi baseada na revisão sobre direcionadores externos, internos, práticas e indicadores de desempenho da GSCM identificados na teoria (modo dedutivo). Também foram elaboradas categorias de associações no qual foram identificadas a partir das respostas a questões 5, 6, 7, 8 (modo indutivo). Além disso, os dois tipos de categorias também foram complementados por informações oriundas dos documentos. A documentação analisada não foi inserida no software, e sim utilizada para corroborar ou complementar as informações repassadas pelos entrevistados.

Para a realização do estudo, procurou-se seguir os critérios de julgamento da qualidade, validade e confiabilidade propostos por Yin (2009). Yin (2009) propõe a realização de quatro testes para determinar a qualidade de estudos de casos, sendo: validade do construto - estabelecimento de medidas operacionais corretas para os conceitos que estão sob estudo; validade interna - estabelecimento de uma relação causal, por meio da qual são mostradas certas condições que levem a outras condições; validade externa - estabelecimento do domínio ao qual as descobertas de um estudo podem ser generalizadas; e a confiabilidade - deve demonstrar que as operações de um estudo, como os procedimentos de coleta de dados, podem ser repetidas, apresentando os mesmos resultados. 
Quanto à validade do construto: foram utilizadas múltiplas fontes de dados, como entrevistas, documentos internos da empresa, documentos públicos, legislações e artigos científicos a fim de relacionar com o encadeamento das evidências e realizar a triangulação dos dados coletados, e através desta técnica ampliar as interpretações feitas pelo pesquisador. Quanto à validade interna: buscou-se confrontar os achados das entrevistas e análises documentais com a teoria existente sobre GSCM. A confidencialidade dos dados coletados ainda é um fator que contribui para a validade interna desta pesquisa. Quanto à validade externa: esta ocorreu confrontando-se os dados obtidos e interpretados durante a pesquisa com a análise do gerente de saúde, meio ambiente e segurança da empresa. Quanto à confiabilidade: com o objetivo de garantir maior confiabilidade, foi elaborado um roteiro semiestruturado com as categorias já elencadas e apresentadas durante a metodologia. Todas as entrevistas foram gravadas, transcritas e armazenadas no software NVIVO. Os documentos obtidos durante a pesquisa foram armazenados em forma digital e listados. Cabe ressaltar que este software foi utilizado principalmente como um banco de dados para as análises de conteúdo e contribuiu para a organização e avaliação desses dados.

Outra forma utilizada para verificar a confiabilidade desta pesquisa está relacionada ao fato de que o software disponibiliza a frequência dos elementos de cada categoria prevista na entrevista semiestruturada. Assim, foi constatado que todos as categorias (linhas) definidas para as perguntas práticas verdes, fatores externos, fatores internos e desempenho ambiental e econômico ao menos uma vez foram discutidas pelos entrevistados (colunas), o que também auxilia na confiabilidade da pesquisa (Figuras 1 a 4, no apêndice).

\section{ANÁLISE E DISCUSSÃO DOS RESULTADOS}

Nesta seção, são apresentadas as práticas de GSCM, os direcionadores internos e externos e indicadores de desempenho encontrados no TECON-Rio Grande (Subseção 4.1) e é apresentada e discutida as associações entre estas partes (Subseção 4.2).

\subsection{Práticas, direcionadores e desempenho na GSCM da TECON}

Nesta seção, são apresentadas as práticas, direcionadores e indicadores de desempenho constatados na TECON-Rio Grande. Em relação às práticas de GSCM desenvolvidas pelo 
TECON uma síntese delas pode ser observada no Quadro 3, onde são apresentadas a prática, as evidências e uma definição da prática no TECON - Rio Grande. Ao se analisar o Quadro 3, pode-se verificar que a TECON- Rio Grande desenvolve as práticas de Gestão ambiental interna / SGA (ZHU et al., 2008; AZEVEDO et al., 2011; HSU et al., 2013), cooperação com o cliente (AZEVEDO et al., 2011; LEE et al., 2013; ARANTES et al., 2014), logística reversa e disposição adequada de resíduos (AZEVEDO et al., 2011; DIABAT; GOVINDAN, 2011; HSU et al., 2013; ARANTES et al., 2014), minimização de resíduos, substituição de insumos. minimização do consumo (AZEVEDO et al., 2011) e gestão de riscos (SOUZA, 2013). As práticas verdes ecodesign (DIABAT; GOVINDAN, 2011; HSU et al., 2013; ARANTES et al., 2014) e diminuir o consumo de materiais perigosos e tóxicos (AZEVEDO et al., 2011), foram identificados na literatura, porém, não foram identificados no caso estudado.

Quadro 3 - Práticas de GSCM encontradas na TECON-Rio Grande

\begin{tabular}{|c|c|c|}
\hline Práticas verdes & Evidências empíricas & $\begin{array}{c}\text { Descrição sintética da } \\
\text { prática }\end{array}$ \\
\hline $\begin{array}{l}\text { Gestão } \\
\text { ambiental } \\
\text { interna }\end{array}$ & $\begin{array}{l}\text { "Sim, tem a ISO 14.001 } 2015 \text { que foi obtida } \\
\text { em dezembro do ano passado". } \\
\text { (ENTREVISTADO 2). } \\
\text { Certificado } \\
\text { pela Bureau Veritas (órgão certificador) em } \\
\text { 30/01/2018, referente a norma ISO } \\
\text { 14.001/2015. }\end{array}$ & $\begin{array}{l}\text { Sistema de gestão } \\
\text { ambiental focado ao } \\
\text { atendimento de legislação } \\
\text { e controle } \text { de } \\
\text { fornecedores. }\end{array}$ \\
\hline $\begin{array}{l}\text { Cooperação } \\
\text { com } \\
\text { cliente }\end{array}$ & $\begin{array}{l}\text { "Algumas atividades de clientes passam por } \\
\text { desenvolvimento de produtos, operações } \\
\text { especiais, então, um exemplo que está se } \\
\text { vendo é o recebimento de fertilizantes } \\
\text { em bag's no lugar do uso de caminhões } \\
\text { (Entrevistado 2). }\end{array}$ & $\begin{array}{l}\text { Adoção de medidas } \\
\text { especiais em cooperação } \\
\text { com o cliente com vistas } \\
\text { a reduzir custos e } \\
\text { impactos ambientais nas } \\
\text { operações. }\end{array}$ \\
\hline $\begin{array}{l}\text { Logística } \\
\text { Reversa } \\
\text { disposição } \\
\text { adequada } \\
\text { resíduos }\end{array}$ & $\begin{array}{l}\text { "Baterias, é um exemplo que eu me lembro } \\
\text { de logística reversa" (Entrevistado 2). }\end{array}$ & $\begin{array}{l}\text { Retorno de resíduo } \\
\text { potencialmente perigoso } \\
\text { parar recicladores } \\
\text { autorizados. }\end{array}$ \\
\hline $\begin{array}{l}\text { Minimização de } \\
\text { resíduos }\end{array}$ & $\begin{array}{l}\text { "Hoje nós estamos também começando com } \\
\text { uma parte de compostagem, pelo estudo e, } \\
\text { nós seremos o primeiro terminal a realizar a } \\
\text { compostagem na área portuária." } \\
\text { (Entrevistado } 1 \text { ). } \\
\text { Autorização Geral FEPAM } 46 / 2017 \text {, emitida } \\
\text { em } 09 / 03 / 2017 \text { e com validade até } 23 / 02 / 2018 \\
\text { autorizou o terminal a construir a área de } \\
\text { compostagem. }\end{array}$ & $\begin{array}{l}\text { Minimização de resíduos } \\
\text { pela utilização da } \\
\text { compostagem e pela } \\
\text { coleta seletiva de } \\
\text { resíduos. }\end{array}$ \\
\hline
\end{tabular}

(CONTINUA) 
(CONTINUAÇÃO)

\begin{tabular}{|c|c|c|}
\hline $\begin{array}{l}\text { Substituição de } \\
\text { Insumos }\end{array}$ & $\begin{array}{l}\text { "Compra dos novos RTG's (Rubber } \\
\text { Tire Gantry) [...] Daqui para frente é uma } \\
\text { certeza que os novos RTG's comprados serão } \\
\text { elétricos [em vez de utilizar diesel]" } \\
\text { (Entrevistado 4). }\end{array}$ & $\begin{array}{l}\text { Substituição da energia a } \\
\text { partir do diesel por } \\
\text { eletricidade. }\end{array}$ \\
\hline Gestão de riscos & $\begin{array}{l}\text { "O terminal trabalha junto com várias } \\
\text { empresas [...]. Se houver algum problema } \\
\text { com alguma das empresas que trabalham na } \\
\text { beira da água, com vazamento de óleo ao mar, } \\
\text { essas empresas todas trabalham junto para } \\
\text { não ter nenhum problema" (Entrevistado } 1 \text { ). }\end{array}$ & $\begin{array}{lrr}\text { Mapeamento de riscos } \\
\text { por } & \text { processo. } \\
\text { Caracterização } & \text { de } \\
\text { cenários que } & \text { possam } \\
\text { impactar a } & \text { empresa. } \\
\text { Atuação coletiva } & \text { com } \\
\text { demais empresas } & \text { do } \\
\text { Porto. } & & \end{array}$ \\
\hline $\begin{array}{l}\text { Minimização do } \\
\text { consumo }\end{array}$ & $\begin{array}{l}\text { "[...] alguns equipamentos já foram } \\
\text { especificados para ter um dispositivo que } \\
\text { quando o equipamento não estiver operando, } \\
\text { ele automaticamente reduz a rotação dele para } \\
\text { níveis bem baixos" (Entrevistado 2). }\end{array}$ & $\begin{array}{l}\text { Relacionada com o } \\
\text { controle do consumo de } \\
\text { diesel e energia elétrica. }\end{array}$ \\
\hline
\end{tabular}

Fonte: elaboração própria.

Os direcionadores externos da GSCM observados no TECON- Rio Grande estão discutidos no Quadro 4. Ao se analisar o Quadro 4 pode-se verificar que a TECON- Rio Grande recebe pressões para adoção de GSCM de: medidas regulamentares (CHIEN; SHIH, 2007; DIABAT; GOVINDAN, 2011; HSU et al., 2013; JABBOUR; SOUZA, 2015); vizinhança (JABBOUR; SOUZA, 2015); bancos; e bolsa de valores e acionistas; e pressões dos clientes (CHIEN; SHIH, 2007; DIABAT; GOVINDAN, 2011; HSU et al., 2013; JABBOUR; SOUZA, 2015). Os direcionadores externos fornecedores (DIABAT; GOVINDAN, 2011) e concorrentes (CHIEN; SHIH, 2007; DIABAT; GOVINDAN, 2011; HSU et al., 2013; JABBOUR; SOUZA, 2015) foram citadas na literatura, porém não foram identificados na empresa.

Quadro 4 - Direcionadores externos encontrados na TECON-Rio Grande

\begin{tabular}{|c|c|c|}
\hline Externos & Evidências empíricas & $\begin{array}{c}\text { Descrição do } \\
\text { direcionador } \\
\text { externo }\end{array}$ \\
\hline $\begin{array}{l}\text { Medidas } \\
\text { regulamentares }\end{array}$ & $\begin{array}{l}\text { "Primeiro lugar, requisito legal, lei. Tem que } \\
\text { cumprir, de qualquer forma tem que atender } \\
\text { todas as leis ambientais, se não estiver } \\
\text { atendendo, tem um prazo para atender bem e os } \\
\text { órgãos reguladores que aí vem: IBAMA, } \\
\text { FEPAM- que é o órgão estadual, órgão } \\
\text { municipal, capitania dos Portos, } \\
\text { Superintendência do Porto, ANTAC" } \\
\text { (Entrevistado 1). }\end{array}$ & $\begin{array}{l}\text { Demanda legal } \\
\text { para adequação } \\
\text { ambiental. }\end{array}$ \\
\hline
\end{tabular}

(CONTINUA) 


\section{(CONTINUAÇÃO)}

\begin{tabular}{|c|c|c|}
\hline $\begin{array}{l}\text { Pressões do } \\
\text { cliente }\end{array}$ & $\begin{array}{l}\text { "Os navios, querem saber o que a gente faz, eles } \\
\text { querem um equipamento de } 1^{\circ} \text { mundo, eles } \\
\text { querem um terminal que atenda igual ao resto } \\
\text { do mundo. Nos perguntam, toda a hora, se a } \\
\text { gente tem ou não tem [SGA], e se tem ou não tem } \\
\text { eles querem comprovações de cada item, sobre o } \\
\text { que que a gente faz resíduo, o que que a gente faz } \\
\text { com a energia, se a gente polui". (Entrevistado } \\
\text { 1). }\end{array}$ & $\begin{array}{l}\text { Empresas } \\
\text { proprietárias dos } \\
\text { navios, (principal } \\
\text { cliente) questiona } \\
\text { as práticas verdes } \\
\text { desenvolvidas } \\
\text { pela empresa. }\end{array}$ \\
\hline Vizinhança & $\begin{array}{l}\text { "Então, pensando do ponto de vista de nossa } \\
\text { reponsabilidade social e sem fugir do negócio, } \\
\text { como é que a gente pode desenvolver essa } \\
\text { sociedade local e consequentemente ter nela um } \\
\text { parceiro? A gente faz já iniciativas com relação } \\
\text { a resposta a emergência, a proteção deles ligada } \\
\text { diretamente ao risco, acho importante pensar } \\
\text { dessa maneira, mas também buscar a } \\
\text { oportunidade" (Entrevistado 5). }\end{array}$ & $\begin{array}{lr}\text { Demanda } & \text { da } \\
\text { vizinhança } & \text { por } \\
\text { práticas } & \text { de } \\
\text { segurança. } & \end{array}$ \\
\hline Bancos & $\begin{array}{l}\text { "Eu diria que talvez a pressão maior de órgãos } \\
\text { financiadores. Então, quando a empresa vai } \\
\text { requerer algum empréstimo, com organismos } \\
\text { nacionais ou internacionais, normalmente } \\
\text { existem questionários bem complexos das } \\
\text { questões relativas às questões ambientais" } \\
\text { (Entrevistado 2). }\end{array}$ & $\begin{array}{lr}\text { Demanda } & \text { dos } \\
\text { bancos } & \text { por } \\
\text { práticas } & \text { de } \\
\text { GSCM } & \text { para } \\
\text { liberação } & \text { de } \\
\text { financiamentos. }\end{array}$ \\
\hline $\begin{array}{lr}\text { Bolsa } & \text { de } \\
\text { valores } & \mathrm{e} \\
\text { acionistas } & \end{array}$ & $\begin{array}{l}\text { "O investidor, acionista fala muito alto essa } \\
\text { linguagem [Práticas verdes] e que tem uma } \\
\text { tendência de ser cada vez mais influenciado para } \\
\text { demandar isso nos negócios onde ele bota } \\
\text { dinheiro. Então a gente vê isso acontecendo. Por } \\
\text { exemplo o CDP (Carbon Disclosure Program), } \\
\text { que procura medir a intensidade de carbono das } \\
\text { empresas e incentiva os investidores a preferirem } \\
\text { a investirem o seu dinheiro em empresas com } \\
\text { menor intensidade de emissão de gás carbônico" } \\
\text { (Entrevistado 5). }\end{array}$ & $\begin{array}{lr}\text { Demanda } & \text { dos } \\
\text { investidores } & \text { por } \\
\text { práticas } & \text { de } \\
\text { GSCM para } & \text { a } \\
\text { tomada } & \text { de } \\
\text { decisão } & \text { de } \\
\text { investimento } & \text { em } \\
\text { ações. }\end{array}$ \\
\hline
\end{tabular}

Fonte: elaboração própria.

Os direcionadores internos da GSCM identificados estão no Quadro 5. Ao se analisar o Quadro 5 pode-se verificar a presença de direção comprometida (JABBOUR e SOUZA, 2015; LUTHRA et al., 2016; FRANCO et al., 2017), disponibilidade de recursos financeiros (JABBOUR; SOUZA, 2015; LUTHRA et al., 2016), recursos humanos qualificados para a implementação da GSCM (ZHU et al., 2008; JABBOUR; SOUZA, 2015; LUTHRA et al., 2016), disponibilidade de recursos tecnológicos (JABBOUR; SOUZA, 2015), que direcionam a implementação da GSCM na TECON - Rio Grande. 
Quadro 5 - Direcionadores internos encontrados na TECON-Rio Grande

\begin{tabular}{|c|c|c|}
\hline $\begin{array}{c}\text { Direcionadores } \\
\text { Internos }\end{array}$ & Evidências empíricas & $\begin{array}{l}\text { Descrição sintética do } \\
\text { direcionador interno }\end{array}$ \\
\hline Direção & $\begin{array}{l}\text { "Sim, nós temos a política nossa, assinada, } \\
\text { não só pelo corporativo, mas também com a } \\
\text { nossa diretoria do terminal mesmo, que tem } \\
\text { que cumprir essa parte de meio ambiente, é } \\
\text { firmado e mais algumas, como vou te dizer, } \\
\text { vários protocolos internos demonstrando } \\
\text { que a gente está assumindo o que a gente } \\
\text { está dizendo que vai fazer" (Entrevistado } \\
\text { 1). } \\
\text { Política ambiental no site da empresa. }\end{array}$ & $\begin{array}{l}\text { Compromisso da alta } \\
\text { liderança para a adoção } \\
\text { de práticas verdes. }\end{array}$ \\
\hline $\begin{array}{l}\text { Disponibilidade } \\
\text { de recursos } \\
\text { financeiros }\end{array}$ & $\begin{array}{l}\text { "[...] a gente sempre faz uma demanda } \\
\text { pedindo já o dinheiro antecipado para tudo } \\
\text { que a gente quer fazer no futuro e o que a } \\
\text { gente tem que atender" (Entrevistado } 1 \text { ). }\end{array}$ & $\begin{array}{lr}\text { Disponibilidade } & \text { de } \\
\text { recursos financeiros para } \\
\text { implementação } r \text { de } \\
\text { práticas, r novas } \\
\text { tecnologias e recursos } \\
\text { humanos comprometidos } \\
\text { com a GSCM. }\end{array}$ \\
\hline $\begin{array}{l}\text { Disponibilidade } \\
\text { de recursos } \\
\text { humanos }\end{array}$ & $\begin{array}{l}\text { "O TECON investiu alto (em recursos } \\
\text { humanos) [...]. E mais difícil que tentar } \\
\text { educar o povo (Entrevistado 1). } \\
\text { "Mais ainda, por conta deste corpo todo } \\
\text { muito bem qualificado, há inclusive } \\
\text { recursos externos que estão ao alcance do } \\
\text { terminal. Como a própria universidade, } \\
\text { como outras instituições como parceiros } \\
\text { comerciais e empresariais daqui da região" } \\
\text { (Entrevistado 5). }\end{array}$ & $\begin{array}{l}\text { Recursos humanos com } \\
\text { qualificação técnica para } \\
\text { o atendimento da } \\
\text { legislação aplicável à } \\
\text { Saúde, Meio Ambiente e } \\
\text { Segurança. }\end{array}$ \\
\hline $\begin{array}{l}\text { Disponibilidade } \\
\text { de recursos } \\
\text { tecnológicos }\end{array}$ & $\begin{array}{l}\text { "E a gente com software também, a gente } \\
\text { consegue enviar os equipamentos para tal } \\
\text { lugar, ele não vai mais aleatoriamente do } \\
\text { cais até o pátio e volta do cais até o pátio. } \\
\text { Ele vai até o pátio e se no meio do caminho } \\
\text { surgir um trabalho ele já é mandado para } \\
\text { aquele outro serviço, para evitar que vá até } \\
\text { o cais e volte de novo para o pátio à toa. } \\
\text { [Este software] consegue diminuir a } \\
\text { quantidade de combustível [evitando que] o } \\
\text { equipamento } \\
\text { (ENTREVISTADO 1). }\end{array}$ & $\begin{array}{l}\text { Capacidades para } \\
\text { implantar inovações } \\
\text { tecnológicas } \\
\text { minimizadoras do uso de } \\
\text { recursos naturais. } \\
\text {. }\end{array}$ \\
\hline
\end{tabular}

Fonte: elaboração própria.

Os direcionadores internos da GSCM identificados estão no Quadro 6. Ao se analisar esse quadro pode-se verificar a presença que a TECON - Rio Grande utiliza os seguintes indicadores ambientais: efluentes (ANTONOV; SELLITTO, 2011), legislação ambiental, 
resíduos sólidos, emissões atmosféricas e recursos naturais (CHIEN; SHIH, 2007; ANTONOV; SELLITTO, 2011) e redução de riscos (AZEVEDO et al., 2011).

Quadro 6 - Indicadores de desempenho ambiental do TECON-Rio Grande

\begin{tabular}{|c|c|c|}
\hline Indicador & Evidências empíricas & Descrição sintética \\
\hline Efluentes & $\begin{array}{l}\text { Licença junto à FEPAM, sob o número } \\
3241 / 2016 \text { DL e com validade até 14/01/2019. } \\
\text { A empresa necessita realizar análise da caixa } \\
\text { separadora óleo/água, conforme } \\
\text { (Condicionante Ambiental - Efluente). Durante } \\
\text { a entrevista também foi apresentado laudo que } \\
\text { comprova essas análises, sendo ele: Laudo } \\
\text { Analítico BQ180268/18, de 27/04/2018. }\end{array}$ & $\begin{array}{l}\text { Indicador de atendimento } \\
\text { a legislação de tratamento } \\
\text { de efluentes. }\end{array}$ \\
\hline Legislação & $\begin{array}{l}\text { "A legislação é monitorada através de um } \\
\text { software. Ela é avaliada pelos diversos setores, } \\
\text { se está sendo atendido ou não e se não está } \\
\text { sendo atendido, para criar planos de ação para } \\
\text { o seu atendimento" (Entrevistado 2). }\end{array}$ & $\begin{array}{l}\text { Monitoramento via } \\
\text { software da legislação } \\
\text { aplicável, bem como } \\
\text { possuir indicador e meta } \\
\text { sobre este atendimento. }\end{array}$ \\
\hline $\begin{array}{l}\text { Resíduos } \\
\text { sólidos }\end{array}$ & $\begin{array}{l}\text { "Nós temos a parte de desempenho nosso } \\
\text { [ambiental] que é a parte de gestação de } \\
\text { resíduos, que a gente tem que ter um } \\
\text { desempenho e demonstrar o que está } \\
\text { acontecendo" (ENTREVISTADO 1). }\end{array}$ & \begin{tabular}{lr}
\multicolumn{2}{l}{ Indicador de } \\
à legislação de & resíduos \\
sólidos, e & ações \\
complementares, & como \\
por exemplo & a \\
compostagem. & \\
\end{tabular} \\
\hline $\begin{array}{c}\text { Emissões } \\
\text { Atmosféricas }\end{array}$ & $\begin{array}{l}\text { Relatório técnico do monitoramento da } \\
\text { qualidade do ar, realizado em janeiro/18. } \\
\text { Site da empresa Wilson Sons, controladora do } \\
\text { TECON Rio Grande, que realiza } \\
\text { o levantamento de geração dos gases de efeito } \\
\text { estufa (GEE) }\end{array}$ & $\begin{array}{l}\text { Indicadores da qualidade } \\
\text { do ar e gases de efeito } \\
\text { estufa. }\end{array}$ \\
\hline $\begin{array}{l}\text { Recursos } \\
\text { naturais }\end{array}$ & $\begin{array}{l}\text { "Sim. Consumo de água, consumo de energia } \\
\text { elétrica, emissão de gás de efeito estufa" } \\
\text { (Entrevistado 2). }\end{array}$ & $\begin{array}{l}\text { Indicadores do consumo } \\
\text { de água, energia elétrica, } \\
\text { diesel e energia elétrica. }\end{array}$ \\
\hline $\begin{array}{l}\text { Redução de } \\
\text { riscos }\end{array}$ & $\begin{array}{l}\text { "Sim, a empresa mapeou por atividade [os } \\
\text { riscos], por função, dentro da empresa e por } \\
\text { local e isso estão todos mapeados" } \\
\text { (Entrevistado 2). }\end{array}$ & $\begin{array}{l}\text { Presença de mapeamento } \\
\text { de processos de riscos, } \\
\text { cenários de alta } \\
\text { complexidade e planos de } \\
\text { ações para situações de } \\
\text { risco. }\end{array}$ \\
\hline
\end{tabular}

Fonte: elaboração própria.

No Quadro 7 verifica-se que a TECON - Rio Grande faz uso dos indicadores econômicos diferenciação e redução de custos (CHIEN; SHIH, 2007). Na empresa, não foram identificados os indicadores aumento na margem de lucro e aumento na participação de mercado (CHIEN; SHIH, 2007). O indicador diferenciação foi relatado durante as entrevistas e não foi identificado na revisão de literatura realizada sobre GSCM. 
Quadro 7 - Indicadores econômicos da TECON-Rio Grande

\begin{tabular}{|c|c|c|}
\hline Redução de Custos & $\begin{array}{l}\text { "Só o que eu tenho são indicadores. Com } \\
\text { relação à energia, o nosso sistema elétrico todo } \\
\text { ele é online, eu consigo saber o consumo } \\
\text { instantâneo que o terminal está tendo hoje, eu } \\
\text { controlo curva de demanda podendo o terminal } \\
\text { ser desligado setorialmente se ultrapassada a } \\
\text { demanda, podendo ser automático ou manual. E } \\
\text { o cruzamento de números, produtividade x } \\
\text { litros diesel / movimento" (Entrevistado 3). }\end{array}$ & $\begin{array}{l}\text { Indicadores } \quad \text { de } \\
\text { redução de custos } \\
\text { dos } \quad \text { principais } \\
\text { insumos (energia } \\
\text { elétrica e diesel). }\end{array}$ \\
\hline Difere & $\begin{array}{l}\text { "Adoção do CONTESC [Terminal de } \\
\text { Contêineres de Santa Clara], porque com a } \\
\text { adoção do CONTESC, além de se tornar uma } \\
\text { ferramenta de competitividade, o CONTESC } \\
\text { utiliza como modal a navegação interior" } \\
\text { (Entrevistado 2). }\end{array}$ & $\begin{array}{lr}\text { Novas alternativas } \\
\text { de transporte } \\
\text { aquaviário para } \\
\text { atendimento } \\
\text { necessidades } \\
\text { clientes. }\end{array}$ \\
\hline
\end{tabular}

Fonte: elaboração própria.

\subsection{Associações entre as partes da GSCM}

Para iniciar a apresentação e discussão dos resultados desta seção, iniciamos pelas associações encontradas entre os direcionadores externos e práticas de GSCM; direcionadores internos e práticas de GSCM e para concluir entre as práticas de GSCM e Desempenho. Estes resultados são oriundos das associações identificadas pelos respondentes nas questões 5 até 8 e descritos na seção de metodologia.

Em relação às associações entre direcionadores externos e práticas de GSCM, foi evidenciada uma associação entre medidas regulamentares, pressão dos bancos e pressão dos clientes com a necessidade de implantação de um sistema de gestão ambiental e vizinhança com a gestão de riscos (Quadro 8). A explicação para a associação entre medidas regulamentares, bancos, clientes e SGA está na necessidade de gerenciar um conjunto complexo de normas e práticas socioambientais e um SGA instrumentalizando a gestão destas normas e práticas, o que também facilita o acompanhamento da própria fiscalização pelos órgãos competentes, bancos e clientes destas normas e práticas (MASUDIN et al., 2018). A associação entre a legislação ambiental e o sistema de gestão ambiental é corroborada por Vanalle et al. (2017). Os autores verificaram uma associação positiva entre as pressões institucionais e com a certificação ISO 14001 (VANALLE et al., 2017; WANG et al., 2018). As organizações que enfrentam regulamentações governamentais significativas têm grande probabilidade de realizar iniciativas de GSC que incluam atividades, como a certificação da ISO 14000 (HUANG et al., 2017). Em relação à associação entre a vizinhança e as práticas de gestão de riscos, no processo 
de avaliação e implementação da gestão de riscos ocorre a interação entre a empresa e a comunidade, o que implica em um processo de retroalimentação, e assim pode ocorrer influência mútua entre as partes.

Quadro 8 - Associações entre direcionadores externos e práticas na TECON-Rio Grande

\begin{tabular}{|l|l|}
\hline \multicolumn{1}{|c|}{ Associação } & \multicolumn{1}{c|}{ Evidência } \\
\hline $\begin{array}{l}\text { Medidas } \\
\text { regulamentares } \\
\text { e SGA }\end{array}$ & $\begin{array}{l}\text { "Seria mais ou menos as duas, normalmente o regulador ele pede no } \\
\text { mínimo o atendimento da legislação, mas às vezes, algumas coisas } \\
\text { mais, por exemplo, se existe uma certificação ISO 14.000" } \\
\text { (Entrevistado 2). }\end{array}$ \\
\hline $\begin{array}{l}\text { Pressão dos bancos e } \\
\text { SGA }\end{array}$ & $\begin{array}{l}\text { "E financiamento é a mesma coisa, também querem saber se a gente } \\
\text { está atendendo a legislação. Exatamente isso que eles querem saber. } \\
\text { mar, se está tudo direitinho, se está tudo certinho, tu me garantes } \\
\text { isso" (Entrevistado 1). "Se existem outras práticas, publicação de } \\
\text { inventário de gás efeito estufa, às vezes, o financiador solicita, e isso } \\
\text { não necessariamente está na legislação" (Entrevistado 2). }\end{array}$ \\
\hline $\begin{array}{l}\text { Pressão dos clientes e } \\
\text { SGA }\end{array}$ & $\begin{array}{l}\text { "O navio é o nosso maior cliente. Sem navio não existe o TECON. } \\
\text { Nos perguntam, toda a hora, se a gente tem ou não tem (SGA), e se } \\
\text { tem ou não tem eles querem comprovações de cada item, sobre o } \\
\text { que que a gente faz resíduo, o que a gente faz com a energia, se a } \\
\text { gente polui "(Entrevistado 1). }\end{array}$ \\
\hline $\begin{array}{l}\text { "A gente faz já iniciativas com relação a resposta a emergência, a } \\
\text { de riscos }\end{array}$ & $\begin{array}{l}\text { proteção deles [vizinhança] ligada diretamente ao risco. Acho } \\
\text { importante pensar dessa maneira, mas também buscamos } \\
\text { desenvolver ações a partir da visão deles." (Entrevistado 5). }\end{array}$ \\
\hline
\end{tabular}

Fonte: elaboração própria.

Em relação às associações, entre direcionadores internos e práticas de GSCM (Quadro 9), foi identificado que a disponibilidade de recursos humanos é associada à logística reversa e à disposição de resíduos e à minimização dos resíduos. Observa-se que as ações empreendidas pelos recursos humanos foram associadas a práticas inovadoras implantadas pelas pessoas e que não eram demandadas pela legislação e que exigiam criatividade. Já disponibilidade tecnológica foi associada à minimização do consumo. A tecnologia contribuiu para o controle do consumo de recursos naturais, como no caso o de energia. Por fim, a direção e os recursos financeiros foram associados à substituição de insumos, pois exigiu tomada de decisão para alocação de recursos financeiros destes para a substituição de máquinas e equipamentos que utilizassem insumos ambientalmente mais amigos.

Estas constatações são corroboradas por Huang et al. (2017). Os autores constataram que para implementar com sucesso as iniciativas de GSCM, as empresas devem superar muitas barreiras, incluindo a falta de conhecimento profissional, e recursos humanos dispendiosos (HUANG et al., 2017). Adicionalmente, os autores constaram que quando as empresas 
enfrentam problemas de proteção ambiental, os gerentes respondem oportunamente ao mercado para manter a vantagem competitiva e as vantagens de suas empresas. Essa pressão regulatória, incluindo a das partes interessadas relevantes, aumenta a conscientização dos gerentes em relação à importância das questões ambientais e os motiva a reconsiderar a integração das iniciativas do GSCM em seus processos. A maioria dos programas do GSCM falhariam sem o compromisso dos principais executivos (HUANG et al., 2017).

Quadro 9 - Associações entre direcionadores internos e práticas na TECON-Rio Grande

\begin{tabular}{|l|l|}
\hline \multicolumn{1}{|c|}{ Associação } & \multicolumn{1}{c|}{ Evidência } \\
\hline $\begin{array}{l}\text { Disponibilidade de } \\
\text { recursos humanos } \\
\text { e logística reversa e } \\
\text { disposição de resíduos }\end{array}$ & $\begin{array}{l}\text { "Eu tenho várias iniciativas que trouxe para cá, o programa 5S, a } \\
\text { questão do trapo para contaminação. O projeto de cortar os filtros } \\
\text { lubrificantes e drenar, eu vi em outra empresa e trouxe para cá, o } \\
\text { escorredor de mangueira" (Entrevistado 3). }\end{array}$ \\
\hline $\begin{array}{l}\text { Disponibilidade de } \\
\text { recursos humanos e } \\
\text { minimização dos } \\
\text { resíduos }\end{array}$ & $\begin{array}{l}\text { "E há outras coisas também, essa parte da compostagem, por } \\
\text { exemplo, não tem uma exigência específica, mas isso foi uma pró- } \\
\text { atividade nossa. A gente quer demonstrar que o troço pode ser } \\
\text { melhor do que é." (Entrevistado 1). }\end{array}$ \\
\hline $\begin{array}{l}\text { Disponibilidade de } \\
\text { recursos tecnológicos } \\
\text { e minimização do do } \\
\text { consumo }\end{array}$ & $\begin{array}{l}\text { "Hoje tem as práticas iniciais que foram adotadas é mais na } \\
\text { operação, então, desde desligar os equipamentos quando não estão } \\
\text { em utilização. A manutenção, especificamente, ela faz a } \\
\text { especificação de equipamentos, alguns equipamentos já foram } \\
\text { especificados para ter um dispositivo que quando o equipamento } \\
\text { não estiver operando, ele automaticamente reduz a rotação dele para } \\
\text { níveis bem baixos." (Entrevistado 3). }\end{array}$ \\
\hline $\begin{array}{l}\text { Direção e Recursos } \\
\text { Financeiros com a } \\
\text { substituição de }\end{array}$ & $\begin{array}{l}\text { "A gente já tinha essa perspectiva e este projeto é anterior, nós } \\
\text { tnsumos oito RTG's e queríamos comprar o próximos quatro } \\
\text { elétricos, mas aí precisava de infraestrutura elétrica, subestação, } \\
\text { eletrovia, então, o custo [o valor do investimento] ficou grande para } \\
\text { a implantação e a gente conseguiu fazer agora, no último um ano e } \\
\text { meio convencer a diretoria que é uma boa solução e o retorno do } \\
\text { investimento é grande, em termos de custo do diesel que nos ajudou } \\
\text { e em termos ambientais, com certeza". (Entrevistado 3). }\end{array}$ \\
\hline
\end{tabular}

Fonte: elaboração própria.

Em relação às associações entre as práticas de GSCM e o desempenho ambiental foi evidenciado. Associações entre o SGA e o desempenho no atendimento à legislação ambiental; substituição de insumos e desempenho em emissão atmosférica e recursos naturais; logística reversa e desempenho em efluentes e resíduos sólidos (Quadro 10). A adoção de um sistema de gestão ambiental, principalmente os certificados, como é o caso da ISO 14000 já presume uma intenção em atender a legislação ambiental. Isto ocorre, pois uma das etapas do processo de implantação de um SGA é a identificação e adequação a legislação ambiental pertinente (BARBIERI, 2004). A substituição de insumos, como por exemplo, o óleo diesel utilizado nos equipamentos, por energia elétrica, pode contribuir para redução da emissão de gás carbônico 
nas atividades da empresa, quando substituído pela energia elétrica. Esta associação poderia ser mais bem corroborada, caso a empresa se certificasse que as suas fontes de energia elétrica tivessem origem hidráulica, eólica ou solar. O sistema de logística reversa prevê a coleta separada dos resíduos sólidos e a comercialização ou disposição com empresas credenciadas junto ao órgão de fiscalização, o que contribui para o desempenho em resíduos sólidos.

Essa associação não foi relatada pelos entrevistados, mas há relação entre a minimização do consumo de diesel e energia elétrica e um melhor desempenho ambiental no que tange as emissões atmosféricas. A relação entre minimização do consumo e desempenho ambiental foi verificada na literatura, onde o desempenho ambiental reflete a capacidade das empresas de reduzir as emissões atmosféricas, os resíduos sólidos e os materiais perigosos liberados para o meio ambiente. A implementação de iniciativas do GSC não só melhora o desempenho ambiental, garantindo que uma empresa e seus fornecedores cumpram os regulamentos e requisitos ambientais, mas também reduz custos de transação e substâncias perigosas em resíduos através da gestão eficaz dos fornecedores. Yang et al. (2013) examinaram as empresas de transporte de contêineres em Taiwan e descobriram que práticas verdes internas e colaboração verde externa afetam positivamente o desempenho ecológico (ambiental) dessas empresas.

Quadro 10 - Associações entre práticas e desempenho ambiental na TECON-Rio Grande

\begin{tabular}{|l|l|}
\hline \multicolumn{1}{|c|}{ Associação } & \multicolumn{1}{c|}{ Evidência } \\
\hline $\begin{array}{l}\text { Sistema de gestão } \\
\text { ambiental e } \\
\text { desempenho no } \\
\text { atendimento a } \\
\text { legislação ambiental }\end{array}$ & $\begin{array}{l}\text { Presença de software para avaliar o atendimento legal de } \\
\text { legislações que são pertinentes ao serviço da empresa. }\end{array}$ \\
\hline $\begin{array}{l}\text { Substituição de } \\
\text { insumos e desempenho } \\
\text { em emissão atmosférica } \\
\text { e recursos naturais }\end{array}$ & $\begin{array}{l}\text { "Estamos modificando o parque de equipamentos de RTG's para } \\
\text { ERTG's, uma das funções é diminuir as emissões de carbono, e } \\
\text { reduzir a queimar combustível fóssil. Trocando a energia geradora } \\
\text { diesel para puramente elétrico" (Entrevistado 5) }\end{array}$ \\
\hline $\begin{array}{l}\text { Logística reversa e } \\
\text { desempenho em } \\
\text { resíduos sólidos }\end{array}$ & $\begin{array}{l}\text { "Como eu disse, vai depender muito de como é a movimentação, } \\
\text { mas administrativamente o nosso orgânico é muito grande, porque } \\
\text { temos refeitório aqui dentro. E aí os banheiros também geram uma } \\
\text { parte de orgânico. Nós temos a parte de desempenho nosso } \\
\text { (ambiental) que é a parte de geração de resíduos, que a gente tem } \\
\text { que ter um desempenho e demonstrar o que está acontecendo, (...)" } \\
\text { (Entrevistado 1). }\end{array}$ \\
\hline $\begin{array}{l}\text { Logística reversa } \\
\text { desempenho } \\
\text { efluentes }\end{array}$ & "No caso, o terminal faz reaproveitamento de água e que causa um \\
empacto positivo ou reduzem o nosso impacto negativo, no caso \\
do reuso da água, no projeto águas limpas. Então, isso é muito \\
positivo. Mas não é crítico para este pedaço da cadeia" \\
(Entrevistado 5).
\end{tabular}

(CONTINUA) 


\section{(CONTINUAÇÃO)}

Minimização do Redução do consumo de diesel e um melhor desempenho consumo e desempenho ambiental no que tange às emissões atmosféricas (Inferência sobre em emissão atmosférica a empresa).

Fonte: elaboração própria.

Em relação às associações entre as práticas de GSCM e o desempenho econômico e ambiental foi evidenciado, associações entre cooperação com cliente e desempenho em diferenciação; de minimização de resíduos com desempenho em redução de custos e resíduos sólidos; minimização do consumo com o desempenho em redução de custos e recursos naturais; substituição de insumos com o desempenho em redução de custos; e minimização do consumo com o desempenho em redução de custos e riscos (Quadro 11).

A cooperação com clientes possibilitou criar uma unidade de negócios da TECON, que foi a criação de um terminal fluvial, o que caracteriza uma estratégia de diferenciação. A partir das necessidades de redução de custo do cliente, redução das emissões de gases poluentes, cooperação entre as partes e considerando a natureza do negócio da TECON, foi então possível implementar a estratégia de negócio.

As práticas de minimização de resíduos, minimização do consumo e substituição de insumos permitiram que a empresa obtivesse redução de custos, como por exemplo o reaproveitamento dos resíduos orgânicos reduziram os custos de disposição adequada, assim como contribuíram para a menor compra de fertilizantes para uso nos jardins da empresa; os softwares de controle de energia e manutenção reduziram os gastos com estes insumos; a substituição do óleo diesel pela energia elétrica reduziu os custos de operação dos equipamentos. Estes argumentam, corroboram os resultados de Zhu et al. (2013) de que as práticas do GSCM melhoram indiretamente o desempenho econômico das empresas através do desempenho ambiental. Em síntese, estes resultados contribuem para esclarecer se há uma relação entre a GSCM e o desempenho econômico e sobre quais práticas seriam benéficas para o desempenho econômico (VANALLE et al., 2017). Entretanto, não foi observado que estas mesmas práticas estejam associadas à possibilidade de a empresa conseguir maiores preços pelos serviços prestados. Porém, pode-se atribuir que as práticas ambientais são um critério que qualifica a empresa a acessar certos clientes, ao menos os que solicitam informações sobre o sistema de gestão ambiental.

Adicionalmente, cabe ressaltar que foi identificada uma relação entre o desempenho ambiental e econômico, visto que houve a redução de custos associada a uma melhora no desempenho ambiental. Porém, Huang et al. (2017) indicam que a relação entre as iniciativas e 
o desempenho do GSCM tem sido extensivamente estudada, mas os resultados são inconclusivos. Entretanto, foi identificado que dependendo da prática verde utilizada, pode-se ter um desempenho ambiental atrelado ao desempenho econômico. Por exemplo, as práticas de minimização do consumo e substituição de insumos levam a uma melhora do desempenho ambiental e econômico.

Quadro 11 - Associações entre práticas e desempenho econômico na TECON-Rio Grande

\begin{tabular}{|c|c|}
\hline Associação & Evidência \\
\hline $\begin{array}{l}\text { Cooperação com } \\
\text { cliente e desempenho } \\
\text { em diferenciação }\end{array}$ & $\begin{array}{l}\text { "Com cliente é a adoção do CONTESC (Terminal de Contêineres } \\
\text { e Santa Clara), porque com a adoção do CONTESC, além de se } \\
\text { tornar uma ferramenta de competitividade, o CONTESC utiliza } \\
\text { como modal a navegação interior. Então, a ideia é a medida que se } \\
\text { tem esse modal se utilizando se conseguir tirar caminhões da } \\
\text { estrada e obviamente todos os recursos. transporte, na época foi } \\
\text { feito um balanço em termos de consumo energético e de geração de } \\
\text { CO2 e quando se divide a geração do transporte lacustre por } \\
\text { contêiner transportado ela é várias vezes menor de quando } \\
\text { transportado por caminhão. Então, além de se tornar estratégico, } \\
\text { por blindar a saída de contêineres pelos portos de Santa Catarina, } \\
\text { ao mesmo tempo ele trabalha na redução das emissões de carbono. } \\
\text { E isso não está no fornecimento, mas está lá nos clientes, então é } \\
\text { uma opção estratégica que o TECON acabou criando para } \\
\text { favorecer a questão comercial e a questão ambiental." } \\
\text { (Entrevistado 2) }\end{array}$ \\
\hline $\begin{array}{l}\text { Minimização de } \\
\text { resíduos e desempenho } \\
\text { na redução de custos e } \\
\text { resíduos sólidos }\end{array}$ & $\begin{array}{l}\text { "Um exemplo é a compostagem. A compostagem é uma prática } \\
\text { legal e que ao mesmo tempo se viabiliza pela redução de alguns } \\
\text { custos." (Entrevistado 2). }\end{array}$ \\
\hline $\begin{array}{l}\text { Minimização } \\
\text { do consumo e } \\
\text { desempenho na } \\
\text { redução de custos e } \\
\text { recursos naturais }\end{array}$ & $\begin{array}{l}\text { "Tenho o SAP que me dá uma base sólida de custos. Eu não tenho } \\
\text { onde largar um centavo sem justificativa. Com relação à energia, o } \\
\text { nosso sistema elétrico todo ele é online, eu consigo saber o } \\
\text { consumo instantâneo que o terminal está tendo hoje, eu controlo } \\
\text { curva de demanda podendo o terminal ser desligado setorialmente } \\
\text { se ultrapassada a demanda, podendo ser automático ou manual. Por } \\
\text { discussão com armadores, os reefers não são mais desligados. Nós } \\
\text { tínhamos um gerenciamento de energia em que reduzimos em 50\% } \\
\text { o custo de energia" (Entrevistado 3). }\end{array}$ \\
\hline $\begin{array}{l}\text { Substituição } \\
\text { de insumos e } \\
\text { desempenho na } \\
\text { redução de custos }\end{array}$ & $\begin{array}{l}\text { “(...) nós tínhamos oito RTG’s e queríamos comprar o próximos } \\
\text { quatro elétricos, mas aí precisava de infraestrutura elétrica, } \\
\text { subestação, eletrovia, então, o custo [investimento]ficou grande } \\
\text { para a implantação e a gente conseguiu fazer agora, no último um } \\
\text { ano e meio convencer a diretoria que é uma boa solução e com } \\
\text { melhor retorno do investimento.” (Entrevistado 3). }\end{array}$ \\
\hline $\begin{array}{l}\text { Gestão de riscos e } \\
\text { desempenho na } \\
\text { redução de custos e } \\
\text { riscos }\end{array}$ & $\begin{array}{l}\text { "A gente vê em outros terminais uma série de acidentes. A gente } \\
\text { está em uma etapa que a gente vê isso. O cara deve estar } \\
\text { indenizando família, justiça, versus um projeto que a gente tem aqui } \\
\text { de segurança." (Entrevistado 4) }\end{array}$ \\
\hline
\end{tabular}

Fonte: elaboração própria. 
Cabe destacar que foram identificadas duas outras exceções de associações para além das três discutidas até aqui, que foram entre direcionadores externos e internos se associando com as práticas de GSCM e esta última com os indicadores de desempenho ambiental e econômico.

Foi constatado que os direcionadores externos, medidas regulamentares, bolsa de valores e acionistas e pressão dos bancos se associam diretamente com os indicadores de desempenho ambiental de cumprimento da legislação ambiental e emissão atmosférica (Quadro 12). Pressões regulamentares e da sociedade (como bancos e acionistas) condicionam a empresa para que ela tenha um mínimo desempenho ambiental satisfatório, o que é refletido na decisão da empresa no atendimento de requisitos legais aplicáveis à empresa. Isto leva a entender que os atores constituintes dos fatores externos estão mais preocupados com os resultados ambientais da empresa do que propriamente de que forma ela atinge esse desempenho, que no caso, seriam as práticas verdes.

Quadro 12 - Associações entre direcionadores externos e desempenho na TECON

\begin{tabular}{|l|l|}
\hline \multicolumn{1}{|c|}{ Associação } & \multicolumn{1}{c|}{ Evidência } \\
\hline $\begin{array}{l}\text { Bolsa de valores e acionistas } \\
\text { e desempenho em emissão } \\
\text { atmosférica }\end{array}$ & $\begin{array}{l}\text { "Então, a bolsa acaba demandando também a publicação de } \\
\text { balanços, a publicação de balanços ambientais, publicação } \\
\text { de por exemplo, redução de emissões" (Entrevistado 2). }\end{array}$ \\
\hline $\begin{array}{l}\text { Pressão dos bancos e } \\
\text { desempenho em emissão } \\
\text { atmosférica. }\end{array}$ & $\begin{array}{l}\text { "Se existem outras práticas, publicação de inventário de gás } \\
\text { efeito estufa, às vezes o financiador solicita, e isso não } \\
\text { necessariamente está na legislação." (Entrevistado 2) }\end{array}$ \\
\hline $\begin{array}{l}\text { Pressão dos bancos e } \\
\text { desempenho } \\
\text { cumprimento da legislação } \\
\text { ambiental }\end{array}$ & $\begin{array}{l}\text { "E financiamento é a mesma coisa, também querem saber se } \\
\text { a gente está atendendo a legislação. Exatamente isso que eles } \\
\text { querem saber. Se a gente está atendendo a lei, se a gente não } \\
\text { está jogando lixo no mar, se está tudo direitinho, se está tudo } \\
\text { certinho, tu me garantes isso." (Entrevistado 1). }\end{array}$ \\
\hline
\end{tabular}

Fonte: elaboração própria.

Ainda foi evidenciada uma relação entre fatores internos e externos, que é a relação entre a disponibilidade de recursos humanos e medidas regulamentares, pois a empresa entendeu ser necessário ter um corpo técnico qualificado para o atendimento de legislação, bem como algumas legislações obrigam a empresa a ter determinados profissionais (como farmacêutico, enfermeiro, médico, engenheiro). 
Quadro 13 - Associações entre direcionadores internos e externos na TECON-Rio Grande

\begin{tabular}{|l|l|}
\hline \multicolumn{1}{|c|}{ Associação } & \multicolumn{1}{c|}{ Evidência } \\
\hline $\begin{array}{l}\text { Medidas regulamentares e } \\
\text { disponibilidade em recursos } \\
\text { humanos }\end{array}$ & $\begin{array}{l}\text { "Além disso, a própria legislação obriga que se tenham } \\
\text { formações específicas e que esses funcionários sejam } \\
\text { responsáveis técnicos junto aos órgãos anuentes, como por } \\
\text { exemplo, engenheiro de segurança (Responsável técnico } \\
\text { junto ao IBAMA) e farmacêutico (Responsável Técnico } \\
\text { junto a ANVISA)." (Entrevistado 1). }\end{array}$ \\
\hline
\end{tabular}

Fonte: elaboração própria.

\section{CONSIDERAÇÕES FINAIS}

O objetivo geral definido foi o de analisar como os fatores externos e internos contribuem ou não para a adoção das práticas verdes e para o desempenho econômico e ambiental do terminal de containers - TECON Rio Grande com o propósito de contribuir para identificação dos direcionadores internos e externos, práticas ambientais e desempenho econômico e ambiental no setor portuário, assim como identificar e descrever as associações existentes entre essas partes, principalmente sobre quais e como as práticas contribuem para o desempenho ambiental e quais e como contribuem para o desempenho econômico.

Como contribuição teórica principal é proposto um framework complexo de análise da GSCM composto por direcionadores externos, internos, práticas e indicadores de desempenho e associações entre estes quatro elementos (Figura 5). Este framework complexo de análise da GSCM traz contribuições teóricas específicas sobre as partes e sobre as associações. Em relação aos achados sobre as partes (direcionadores externos, internos, práticas e indicadores de desempenho), a expectativa a partir da revisão da literatura que se tinha era de que se encontrariam todos estes elementos no caso estudado, assim como contribuições teóricas específicas, revelou-se que fornecedores e concorrentes não foram identificados como direcionadores externos; ecodesign e minimização de materiais perigosos, práticas estas citadas na literatura também não foram confirmadas no caso estudado; também não se constatou indicadores de lucro e participação de mercado, conforme indicado na literatura. Entretanto, diferentemente da literatura, o caso estudado revelou que a GSCM pode contribuir para a conquista de novos clientes através de uma estratégia de diferenciação de suas atividades com foco nas práticas de cooperação com os clientes, o que sugere a necessidade de estudar este indicador de desempenho econômico em futuras pesquisas. Em relação aos achados sobre as associações, a expectativa a partir da revisão da literatura que se tinha era de que se 
encontrariam associações entre os direcionadores externos e internos diretamente com as práticas de GSCM, que por sua vez se associariam aos indicadores de desempenho, e que foi observado, na maior parte das associações identificadas. Entretanto, este caso traz contribuições teóricas específicas sobre as associações ao revelar associações entre certos direcionadores e certas práticas desenvolvidas, assim como entre as práticas de GSCM e os indicadores de desempenho. Especificamente foi verificado que os direcionadores externos podem condicionar diretamente a presença ou não de indicadores de desempenho adotados pela empresa (p.e. bancos e bolsa associada à presença de indicadores de emissões atmosféricas, assim como a presença ou não de direcionadores internos (medidas regulamentares associada a presença de recursos humanos qualificados). Além disso, revelou que certas práticas têm associação com o desempenho econômico, outras com o desempenho ambiental, assim como outras para ambas as dimensões.

Figura 5 - Framework complexo de análise da GSCM: componentes e associações

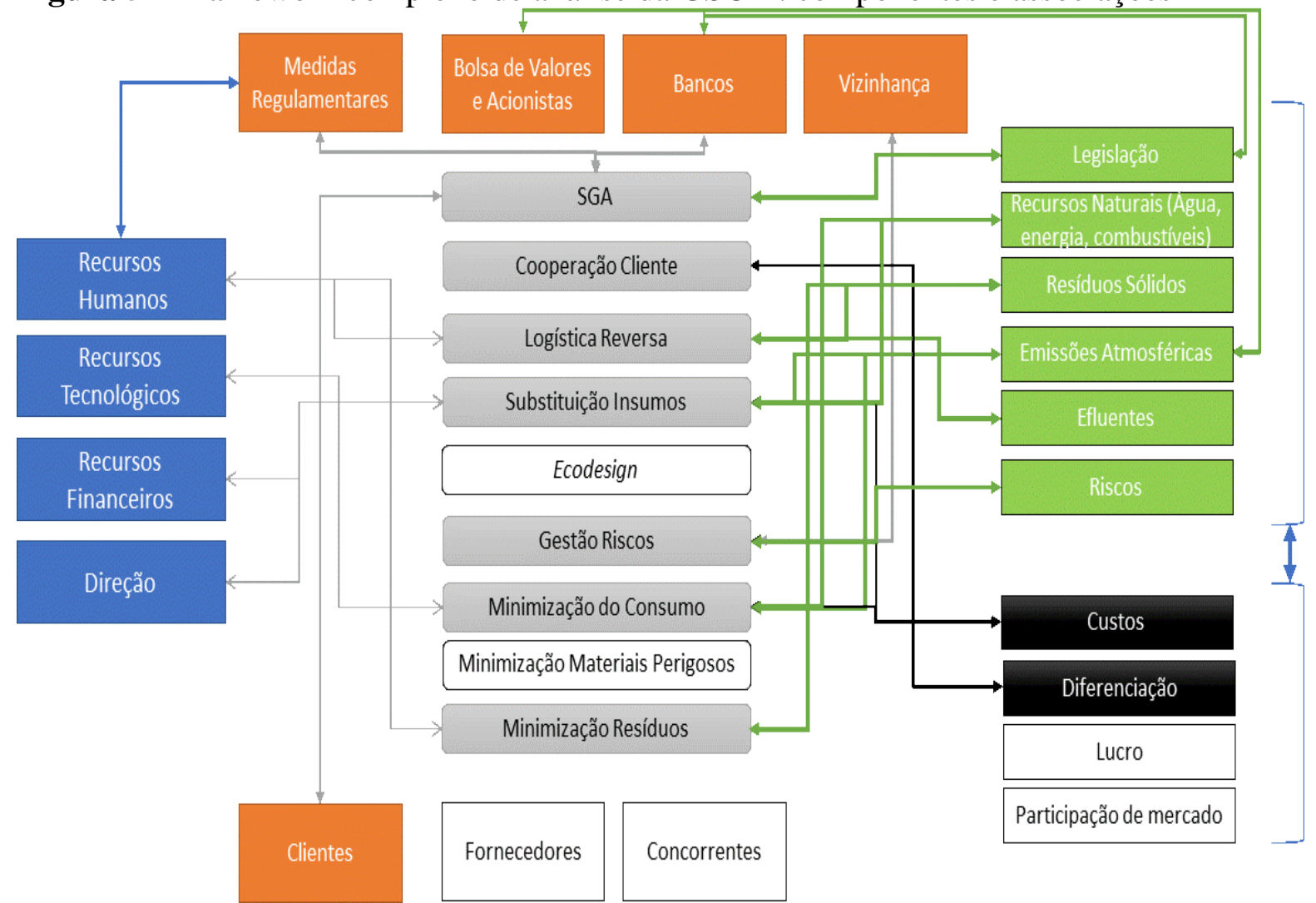

Legenda: Laranja - Direcionadores Externos; Azul: Direcionadores Internos; Cinza: Práticas de GSCM; Verde: Indicadores de Desempenho Ambiental; Preto: Indicadores de Desempenho Econômico; Em Branco: Fatores não observados no estudo de caso e citados na literatura.

Fonte: elaboração própria.

Como uma contribuição gerencial principal, o framework proposto permite a análise da GSCM de forma sistêmica de uma organização. Revela quais os direcionadores internos e externos, as práticas e indicadores de desempenho precisariam ser observados na proposição 
ou aprimoramento da GSCM numa organização, principalmente num contexto de organizações do setor portuário. Traz um conjunto de rotas constituídas pelos elementos e associações entre eles que permite ao analista gerencial propor ações que contribuam, tanto para o desempenho ambiental, quanto para o desempenho econômico da organização, e assim presume-se, implantar ou aprimorar com mais facilidade práticas de GSCM na organização.

Uma limitação na apresentação destes resultados está na impossibilidade de apresentar todas as evidências identificadas no estudo de caso para cada um dos elementos do Sistema de GSCM do sistema, isto devido à necessidade de ampliar demasiadamente a redação do artigo. Por fim, sugere-se expandir este estudo para outras empresas do segmento portuário do país através de métodos que possam medir a contribuição de cada um dos elementos e das associações identificadas no GSCM estudada, considerando que este tipo de serviço empresarial é pouco estudado com relação à GSCM. Uma proposição para esta proposição de pesquisa poderia envolver o Método de Análise Qualitativa Comparativa - QCA (RIHOUX; RAGIN, 2009), já que é um método que permite analisar possíveis combinações de condições causais multiníveis a uma variável de desempenho, mesmo em estudos de casos (DIAS; PEDROZO, 2015).

\section{REFERÊNCIAS}

AGÊNCIA NACIONAL DE TRANSPORTES AQUAVIÁRIOS (ANTAQ). Meio ambiente. 2013. Disponível em: <http://portal.antaq.gov.br/index.php/meio-ambiente/>. Acesso em: 03 jul. 2019.

ANTONOV, P.; SELLITTO, M. A. Avaliação de desempenho ambiental: estudo de caso na indústria papeleira. Revista Produção Online, v. 11, n. 4, p. 1059-1085, 2011. <http://dx.doi.org/10.14488/1676-1901.v11i4.723>.

ARANTES, A. F.; JABBOUR, A. B. L. D. S.; JABBOUR, C. J. C. Adoção de práticas de green supply chain management: mecanismos de indução e a importância das empresas focais. Production, p. 725-734, 2014. <http://dx.doi.org/10.1590/S0103-65132014005000007>.

ASSOCIAÇÃO BRASILEIRA DE NORMAS TÉCNICAS. ABNT NBR ISO 14001. Sistemas de gestão ambiental: especificação e diretrizes para uso. Rio de Janeirp: ABNT, 2015. 
AZEVEDO, S. G.; CARVALHO, H.; MACHADO, V. C. The influence of green practices on supply chain performance: a case study approach. Transportation Research Part E-Logistics and Transportation Review, v. 47, n. 6, p. 850-871, Nov 2011. <http://dx.doi.org/10.1016/j.tre.2011.05.017>.

BARBIERI, J. C. Sistema de Gestão Ambiental. In: BARBIERI, J. C. (Ed.). Gestão ambiental empresarial: conceitos, modelos e instrumentos. São Paulo: Saraiva, 2004. cap. 5, p. 153-208.

CHIEN, M. K.; SHIH, L. H. An empirical study of the implementation of green supply chain management practices in the electrical and electronic industry and their relation to organizational performances. International Journal of Environmental Science and Technology, v. 4, n. 3, p. 383-394, Sum 2007. ISSN 1735-1472.

DELIBERAL, J. P. et al. Environmental Management as a Strategic Capability: a Study on the Furniture Manufacturing Cluster of Southern Brazil. Brazilian Business Review, v. 13, n. 4, p. 124, 2016. <http://dx.doi.org/10.15728/bbr.2016.13.4.6>.

DIABAT, A.; GOVINDAN, K. An analysis of the drivers affecting the implementation of green supply chain management. Resources Conservation and Recycling, v. 55, n. 6, p. 659-667, Apr 2011. <http://dx.doi.org/10.1016/j.resconrec.2010.12.002>.

DIAS, M. F. P.; PEDROZO, E. A. Metodologia de estudo de caso com múltiplas unidades de análise e métodos combinados para estudo de configurações. Iberoamerican Journal of Strategic Management (IJSM). v. 14, p. 23-39, 2015.

FAHIMNIA, B.; SARKIS, J.; DAVARZANI, H. Green supply chain management: A review and bibliometric analysis. International Journal of Production Economics, v. 162, p. 101114, Apr. 2015. <http://doi.org/10.1016/j.ijpe.2015.01.003>.

FRANCO, D.; GANGA, G. M. D.; DE SANTA-EULALIA, L. A. Gestão ambiental em cadeia de suprimentos: revisão sistemática da literatura. Revista Produção Online, v. 17, n. 1, p. 295, 2017. <https://doi.org/10.14488/1676-1901.v17i1.2536>.

GUSMÃO, A. C. F; MARTINI, Luis. C. de. Gestão ambiental na indústria. Rio de Janeiro: SMS Digital, 2009. 224 p

HSU, C. C. et al. Supply chain drivers that foster the development of green initiatives in an emerging economy. International Journal of Operations \& Production Management, v. 33, n. 6, p. 656-688, 2013. <http://dx.doi.org/10.1108/ijopm-10-2011-0401>. 
HUANG, Y. C.; HUANG, C. H.; YANG, M. L. Drivers of green supply chain initiatives and performance evidence from the electrical and electronics industries in Taiwan. International Journal of Physical Distribution \& Logistics Management, v. 47, n. 9, p. 796-819, 2017. <http://dx.doi.org/10.1108/ijpdlm-05-2017-0185>.

JABBOUR, A. B. L. D. S. et al. Esverdeando a cadeia de suprimentos: algumas evidências de empresas localizadas no Brasil. Gestão \& Produção, p. 953-962, 2013. <http://dx.doi.org/10.1590/S0104-530X2013000400014>.

JABBOUR, A. B. L. D. S.; SOUZA, C. L. Oportunidades e desafios para lidar com as barreiras à adoção de práticas de green supply chain management: guidelines à luz de um estudo de múltiplos casos no Brasil. Gestão \& Produção, v. 22, n. 2, p. 295-310, 2015. <http://dx.doi.org/10.1590/0104-530X871-13>.

LEE, S. M. et al. Pressures affecting green supply chain performance. Management Decision, v. 51, n. 8, p. 1753-1768, 2013. <http://dx.doi.org/10.1108/md-12-2012-0841>.

LUTHRA, S.; GARG, D.; HALEEM, A. The impacts of critical success factors for implementing green supply chain management towards sustainability: an empirical investigation of Indian automobile industry. Journal of Cleaner Production, v. 121, p. 142158, 2016. <http://doi.org/10.1016/j.jclepro.2016.01.095>.

MASUDIN, I.; WASTONO, T.; ZULFIKARIJAH, F. The effect of managerial intention and initiative on green supply chain management adoption in Indonesian manufacturing performance. Cogent Business \& Management, v. 5, n. 1, Jun 2018. <http://dx.doi.org/10.1080/23311975.2018.1485212>.

RIHOUX, B.; RAGIN, C. C. Configurational comparative methods: Qualitative comparative analysis (QCA) and related techniques. Los angelies: Sage Publications: 2009.

SILVA JÚNIOR, A. et al. Oportunidades para compras verdes no setor de suprimentos da Petróleo Brasileiro SA. Contextus - Revista Contemporânea de Economia e Gestão, Fortaleza, v. 7, n. 1, p. 69-80, 2009.

SILVEIRA, M. A. P.; RANGEL, F. C.; DA SILVA TRAVASSOS, M. Transferência de informação e conhecimento nas cadeias de autopeças elétricas de reposição e perfis de alumínio para construção civil: um estudo comparativo. Contextus - Revista Contemporânea de Economia e Gestão, v. 8, n. 1, 2010.

SOUZA, C. L. D. Barreiras e motivações à adoção de práticas de green supply chain management: estudo de casos no setor de baterias automotivas. 139 p. Dissertação 
(Mestrado em Engenharia de Produção) - Universidade Estadual Paulista "Júlio de Mesquita Filho, Faculdade de Engenharia de Bauru, Bauru, 2013. Disponível em: <http://hdl.handle.net/11449/93070>. Acesso em: 03 jul. 2019.

SRIVASTAVA, S. K. Green supply-chain management: a state-of-the-art literature review. International Journal of Management Reviews, v. 9, n. 1, p. 53-80, 2007. $<$ http://dx.doi.org/10.1111/j.1468-2370.2007.00202.x>.

TERMINAL DE CONTÊINERES DE RIO GRANDE (TECON). Quem somos. 2017. Disponível em: <http://TECON.com.br/site/content/apresentacao/>. Acesso em 10 fev. 2019

VANALLE, R. M. et al. Green supply chain management: an investigation of pressures, practices, and performance within the Brazilian automotive supply chain. Journal of Cleaner Production, v. 151, p. 250-259, May 2017. <https://doi.org/10.1016/j.jclepro.2017.03.066>.

WANG, Z. Q. et al. Effects of customer and cost drivers on green supply chain management practices and environmental performance. Journal of Cleaner Production, v. 189, p. 673-682, Jul 2018. 〈http://doi.org/10.1016/j.jclepro.2018.04.071>.

YANG, C.-S. et al. The effect of green supply chain management on green performance and firm competitiveness in the context of container shipping in Taiwan. Transportation Research Part E: Logistics and Transportation Review, v. 55, p. 55-73, jan. 2013. $<$ http://doi.org/10.1016/j.tre.2013.03.005>.

YIN, R. Case study research: design and methods. 4. Thousands Oaks: Sage Publications, Inc, 2009.

ZHU, Q. H.; SARKIS, J.; GENG, Y. Green supply chain management in China: pressures, practices and performance. International Journal of Operations \& Production Management, v. 25, n. 5-6, p. 449-468, 2005. <http://doi.org/10.1108/01443570510593148>.

ZHU, Q. H.; SARKIS, J.; LAI, K. H. Confirmation of a measurement model for green supply chain management practices implementation. International Journal of Production Economics, v. 111, n. 2, p. 261-273, feb. 2008. <http://doi.org/10.1016/j.ijpe.2006.11.029>.

ZHU, Q.; SARKIS, J.; LAI, K.-H. Institutional-based antecedents and performance outcomes of internal and external green supply chain management practices. Journal of Purchasing and Supply Management, v. 19, n. 2, p. 106-117, jun. 2013. <http://doi.org/10.1016/j.pursup.2012.12.001>. 


\section{APÊNDICE - FIGURAS 1 A 4}

Figura 1 - Análise confiabilidade entrevistas - práticas verdes

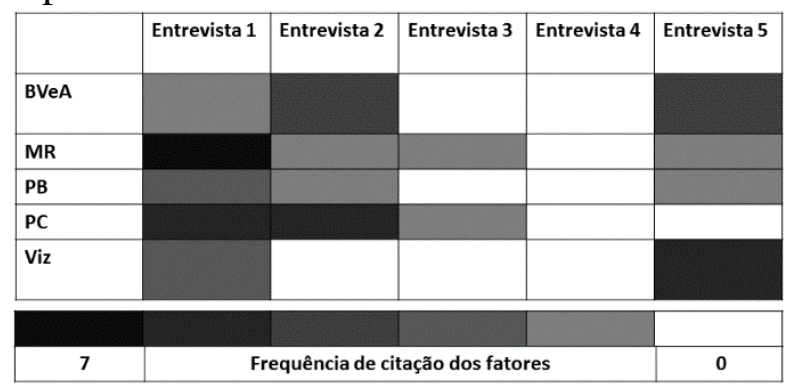

Legenda: BVeA - Bolsa de valores/acionistas; MR Medidas Regulamentares; PB- Pressão dos Bancos ; PC - Pressão dos Clientes; Viz - Vizinhança; En Entrevistado 1 até 5

Fonte: adaptado do NVIVO.

Figura 3 - Análise confiabilidade entrevistas - fatores internos

\begin{tabular}{|l|l|l|l|l|l|}
\hline & Entrevista 1 & Entrevista 2 & Entrevista 3 & Entrevista 4 & Entrevista 5 \\
\hline CC & & & & & \\
\hline GR & & & & & \\
\hline LR & & & & & \\
\hline MC & & & & \\
\hline MR & & & & \\
\hline SGA & & & \\
\hline SI & & & \\
\hline \multicolumn{4}{|l|}{ Frequência de citação dos fatores } & 0 \\
\hline
\end{tabular}

Legenda: CC- Cooperação Clientes; GR-Gestão Riscos; LR-Logística Reversa; MC-Minimização Consumo

SGA-Sistema de Gestão Ambiental; SI-Substituição Insumos; MR- Minimização de Resíduos Fonte: adaptado do NVIVO
Figura 2 - Análise confiabilidade entrevistas - direcionadores externos

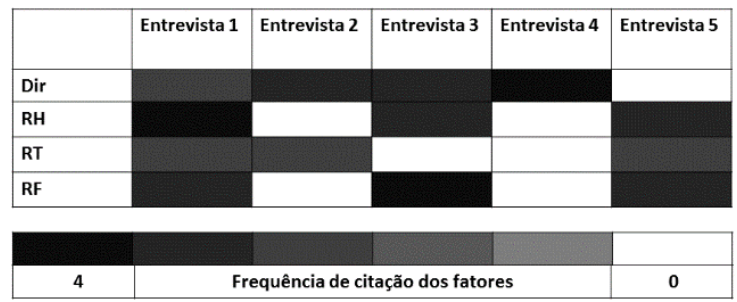

Legenda: Dir - Direção; RF- Recursos Financeiros; RT - Recursos Tecnológicos; RH- Recursos Humanos; En - Entrevistado 1 até 5 Fonte: adaptado do NVIVO

Figura 4 - Análise confiabilidade entrevistas - des. ambiental e econômico
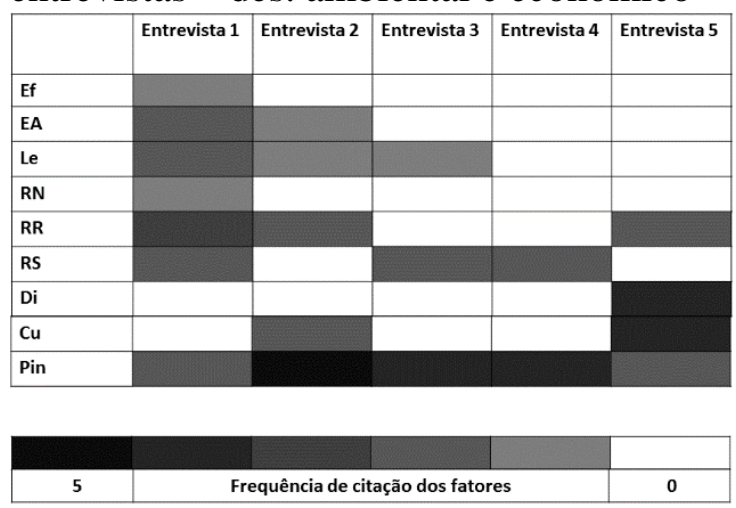

Legenda: Ef-Efluentes, EA-Emissões atmosféricas; Le-Legislação; RN-Recursos Naturais; RRRedução de Riscos; RS-Resíduos Sólidos; DiDiferenciação; Cu-Custos; Pm-Part. Mercado Fonte: adaptado do NVIVO 